\title{
Le charisme des inconnus : Nicoleta Esinencu, Savatie Bastovoi, Vasile Ernu, Dumitru Crudu
}

Hélène Lenz

\section{(2) OpenEdition}

1 Journals

\section{Édition électronique}

URL : https://journals.openedition.org/cher/10583

DOI : $10.4000 /$ cher. 10583

ISSN : 2803-5992

\section{Éditeur}

Presses universitaires de Strasbourg

\section{Édition imprimée}

Date de publication : 1 décembre 2013

Pagination : 243-282

ISBN : 978-2-86820-560-5

ISSN : 1968-035X

\section{Référence électronique}

Hélène Lenz, « Le charisme des inconnus : Nicoleta Esinencu, Savatie Bastovoi, Vasile Ernu, Dumitru Crudu », reCHERches [En ligne], 11 | 2013, mis en ligne le 08 février 2022, consulté le 09 février 2022. URL : http://journals.openedition.org/cher/10583 ; DOI : https://doi.org/10.4000/cher.10583

\section{(c) (i) (8)}

Ce(tte) œuvre est mise à disposition selon les termes de la Licence Creative Commons Attribution Pas d'Utilisation Commerciale - Partage dans les Mêmes Conditions 4.0 International. 


\title{
Le charisme des inconnus: Nicoleta Esinencu, Savatie Bastovoi, Vasile Ernu, Dumitru Crudu
}

\author{
HéLÈNE LENZ \\ Université de Strasbourg
}

\begin{abstract}
A u printemps 2013, le Salon du Livre à Paris invitait la Roumanie. Parmi 27 autres auteurs, Nicoleta Esinencu et Savatie Bastovoï présentaient des livres. Dans la dramaturge née en 1978, le romancier né en 1976, la critique a aussi vu des vedettes dont la notoriété relève d'un intérêt pour leur origine nationale. Une aide occidentale et roumaine a en effet facilité l'émergence internationale de leurs écrits animés par les tensions de leur pays, ancienne partie de l'URSS avant l'indépendance (1991).

Fuck You Europa de Nicoleta Esinencu, rédigé en 2003 avait été déjà présenté au Pavillon roumain de la Mostra de Venise en 2006. Les autres textes joués à Paris y ont été exportés parce qu'en République de Moldavie "la création théâtrale demeure modeste et trouve peu de scènes » (Ribardière, 2012). Le Portail francophone du pays rapproche l'ensemble de la démarche dramaturgique moldave de celle

qui s'exprime dans le Belarus au Théâtre libre de Minsk de Nikolaï Khalezine et Natalia Kaliada, avec une pièce comme 'Génération Jeans'. Dans les deux cas, on se trouve dans des États autrefois intégrés dans l'Union Soviétique, qui tentent d'exister entre l'ancienne puissance dont ils sont séparés et l'Union Européenne voisine qui les attire, la Moldavie plus encore que le Belarus. (Ribardière, 2012)
\end{abstract}

Savatie Bastovoï a ainsi expliqué ses liens avec l'État roumain dont il écrit la langue:

Comme vous voyez, je représente ici la Roumanie quoique je ne sois pas citoyen roumain. Mais il n'y a pas là de confusion car j'ai étudié en Roumanie, je m'y suis formé comme écrivain, j'écris en roumain pour les 
Roumains. Mais c'est de République de Moldavie que je viens, pays dont je suis citoyen mais qui n'est pas représenté au Salon du Livre. (Bastovoi/ Colosimo, 2013: 72-73). ${ }^{1}$

De tels auteurs ont pu être concurrencés sur le terrain de leur représentativité nationale par des Roumains, suggérait Catherine Simon dans Le Monde des Livres du 5 janvier 2012.

De la petite République de Moldavie, ex-confetti de l'Empire soviétique et sœur siamoise de la province roumaine de même nom, on ne connaît en France que de rares écrits. Le violent $K m 7$ de la dramaturge Nicoleta Esinencu a été publié l'an dernier dans le recueil collectif Odessa Transfer. Chroniques de la mer Noire (édité à Lausanne). Des romans en langue roumaine ont été traduits en français: Je suis une baba communiste de Dan Lungu, Chewing-gum de Lucian Teodorovici, Pas question de Dracula de Florin Lazarescu. Mais ces trois auteurs sont de Iasi : ce sont des Roumains de Roumanie. (Simon, 2012).

Entre 1991 et le $\mathrm{XXI}^{\mathrm{e}}$ siècle, les écrivains moldaves ont été confrontés à un chaos politique rendu impossible par l'univers totalitaire sous contrôle policier d'avant la chute soviétique. Ils ont expérimenté la fin de la propagande. Une fois sur le sol roumain, ils ont pu comparer le passé récent des deux pays: - la Moldavie de la Perestroïka (1985) - les traces de la dictature nationalecommuniste Ceaușescu en Roumanie entre 1980 et 1989. Ils ont constaté le discrédit de leurs éducations / formations semblables à celles des autres Soviétiques, l'abaissement de l'orgueil d'un pays immense, le contact avec un Occident décidé à intégrer après 2000 dans une Union européenne élargie des alliés communistes de seconde zone - dont la Roumanie. La déception de voir des Moldaves écartés de l'Eldorado capitaliste et de l'espace de libre circulation où Roumains et Bulgares s'apprêtent à entrer serait la première cause de la violence de Nicoleta Esinencu.

En matière de provocation (...) la jeune écrivaine moldave Nicoleta Esinencu a fait mieux en présentant au pavillon roumain (...) le long poème intitulé FUCK YOU EU-RO-PA. Ce cri de désespoir a beaucoup choqué, pourtant il s'agissait d'une réaction somme toute naturelle devant les frustrations engendrées par les nouvelles frontières qui séparent la Moldavie de l'Europe. (Cazacu, Trifon, 2010: 144).

Dans une interview moldave, l'écrivaine soulignait que Fuck you... rédigé grâce à un séjour d'un an et demi à Stuttgart en résidence internationale

1 L'interview et des échanges avec le public de cette table ronde ont été publiés à Bucarest par la propre maison d'éditions de Savatie Bastovoï, diffusant désormais tous ses écrits. Traduit du roumain par H.Lenz. 
de création ( LLa Solitude») serait publié en Allemagne avant de paraître en roumain. La bourse dont elle avait bénéficié, attribuée à 40 créateurs dont un seul autre Moldave: Octavian Esanu, lui avait permis d'entrer en relations avec 300 artistes. L'agressivité de son expression, la crudité de son langage, était attribuable à un courant propre aux Bessarabiens. Ces derniers souhaitaient vers 2005 imposer auprès des Roumains la volonté d'existence de leur jeune littérature moldave plus directe, marquée par l'influence lexicale russe:

Quand les Bessarabiens installés en Roumanie écrivent, ils sentent la nécessité de faire partie d'un mouvement puissant qui dit les choses directement, de faire une 'littérature-problème'. Ceux qui constituent ce courant sont déjà assez nombreux. Tout le monde évite de le dire. Il s'agit de l'influence de la langue russe, d'un processus qui, même s'il est anormal se révèle pourtant normal, dans une langue accaparée par une autre langue. Aujourd'hui même, j'ai parlé dans la rue à quelqu'un qui m'a dit: «Hai.pa.Baftă davaï». Ces mots sont devenus usuels. Peut-on dire que dire que ces gens ne savent pas parler roumain? Par notre expression, nous révélons comment une langue a été dominée par une autre. Comparez cela avec les américanismes! Dire "week-end» est permis mais si nous disons «privet», nous sommes catalogués comme russes. Ce phénomène est passager (...). La littérature russe a été largement lue et elle le sera encore. ${ }^{3}$ (Rusu / Esinencu, 2005)

En République de Moldavie, ce parti pris coïnciderait avec l'affirmation de l'indépendantisme, d'un nationalisme revendiquant le droit d'ouverture à l'Ouest. Commentant les manifestations de rues du 7 avril 2009 à Chișinau derrière des drapeaux moldaves, roumains, de l'Union Européenne soldées par des dizaines de blessés, plus de cent arrestations, des incendies de bâtiments -, les historiens Matei Cazacu et Nicolas Trifon soulignent la nouvelle forme des revendications nationales. Elles sont impossibles à confondre avec le nationalisme roumain del'avant-deuxième guerre mondiale auquel les courants favorables aux Russes rattachent systématiquement les Moldaves pour les discréditer:

Le ton de la journée était anti-communiste, pro-roumain mais pas antirusse; la grande majorité des participants était en revanche, roumanophone. Pour un «correspondant en Russie d'un quotidien parisien qui connaît bien Chișinău (...) nouveau (était) le refus de nombreux manifestants interrogés de s'exprimer en russe sans montrer pour autant une animosité particulière. Nouveau aussi était l'impact limité des accusations rituelles portées contre

2 La première partie de l'interjection est en roumain, la deuxième en russe.

3 Traduit du roumain par H.Lenz. 
'les fascistes roumains', 'antisémites notoires', accusations dont le caractère grotesque fait de moins en moins mystère, y compris dans les milieux antifascistes internationaux pourtant prompts à relayer sans les vérifier ce genre d'accusations provenant de l'Est.» (Cazacu, Trifon, 2010: 151).

La volonté d'exprimer une génération ignorée semble la première motivation littéraire de Nicoleta Esinencu et Nicoleta Bastovoï. Rédigés et même publiés depuis près de dix ans, leurs textes présentés à Paris se sont d'abord pliés aux pratiques d'un pays où le "comportement générationnel» des intellectuels est constant depuis au moins la période stalinienne (Negură, 2009:295). Cette réception officielle à Paris de deux roumanophones ex-soviétiques peut aussi coïncider avec la volonté de briser les anciens dysfonctionnements d'une communication Est-Ouest aux modalités inchangées depuis le début du communisme soviétique, malgré les modifications étatiques des trente dernières années. Les travaux de Ioana Popa sur les échanges traductologiques entre Est et Ouest montrent bien que trois types de circulation des manuscrits entre monde libre et totalitaire ont caractérisé la période communiste. Un circuit "autorisé», un circuit semiclandestin, un circuit prohibé (samizdat) dont l'analyse concerne aussi les œuvres originales

La politique extérieure d'exportation des écrits par les régimes socialistes (a été) / est doublée par l'existence de mécanismes de réception relevant de la même idéologie politique. L'espace - cible (a été) / est en l'occurrence le champ intellectuel français. Une attention particulière est/ a été prêtée au PCF dont l'appareil idéologique joue un rôle important dans la configuration du transfert littéraire autorisé, par la création de filières d'importation ou de médiateurs littéraires spécifiques, contribuant ainsi à la politisation du transfert et au changement de rapports Est-Ouest. La perspective de l'importation vers la France contribue à réaffirmer la position du champ littéraire français au niveau international et son pouvoir de consécration. (Tiron ${ }^{4}, 2011$ )

On sait que le système soviétique, les régimes socialistes satellites ont instauré une censure repérant pour les pénaliser : les «erreurs idéologico-politiques». Le «censeur interne» (ou autocensure) a rapidement remplacé dans ces pays la censure extérieure. Pour Petru Negură citant l'écrivain Aureliu Busuioc en 2003, "cet ange de l'épaule gauche» est le surveillant auquel «se confrontent tous les écrivains en situation de forte contrainte politique ou économique». Les Moldaves soviétisés auraient été dès la première

4 L'article de Irina Tiron cité a pour référence: Irina Tiron. «Ioana Popa.'Traduire sous contraintes. Littérature et communisme (1947-1989)'.» Lectures (En ligne), Les notes critiques. 2011. Mis en ligne le 16 février 2011. Page consultée le 26 septembre 2013. 
vague de campagne jdanovienne, dès septembre 1946 donc, concernés par deux échéances de leur activité. D’une part, ils pouvaient s'adonner à «une écriture de contrebande» jouant sur les ambiguïtés du discours en raison de l'impossibilité de posséder même «une relative autonomie par rapport à la méthode officielle de création»: le réalisme socialiste (sinon après 1953: dans la littérature "apolitique», folklorique, pour enfants, poésie d'amour autorisée). D’autre part, ils devaient produire activement de la «littérature de propagande» (Negură, 2009: 258-259). Mais aux yeux de l'historien, il n'a pu exister de " littérature de contrebande» en Moldavie de l'époque stalinienne, car: a) la publication de tels écrits y a été rendue impossible, b) les écrivains des années 1940 ont tous été des adhérents volontaires du régime soviétique auxquels ils se sont dévoués. Comme tels, ils n’ont jamais eu intérêt à "trafiquer» les significations à la manière des post-modernes roumains sous Ceausescu aux alentours de 1980 revendiquant notamment un modèle romanesque russe: Le maître et Marguerite de Boulgakov écrit en Union Soviétique entre 1928 et 1940.

Les auteurs moldaves aujourd'hui sont-ils encore tributaires du discours idéologique décrit par Petru Negură? Nous tâcherons d'envisager des points communs aux écrits de Savatie Baștovoi et Nicoleta Esinencu, tous deux programmés par la traduction française pour une circulation ultérieure plus ample. Vasile Ernu dont l'essai Născut in URSS / Né en URSS est un bestseller réédité à Iași $(2006,2007,2010,2013)$ sera mentionné. Récompensé par divers prix, son ouvrage présente des tableaux humoristiques sur les mœurs communes aux Moldaves et à l'ensemble soviétique -. Il a déjà été traduit en Russie (2007), en Bulgarie (2009), en Espagne et Italie (2010), en Hongrie et Géorgie (2011). Enfin, le roman de Dumitru Crudu: Un american la Chișinău / Un Américain à Chișinău publié en février 2013 à Bucarest, sera commenté pour l'originalité avec laquelle il explore des thèmes moldaves à peine effleurés par les autres auteurs. Elle renvoie à l'éclatante personnalité littéraire de ce fondateur du fracturisme des années 2000, dont le manifeste traduit en français sera publié en annexe.

\section{Poétiques de l'enfance}

Les lapins ne meurent pas de Savatie Bastovoi traduit avant le Salon du Livre se désigne comme un récit d'enfance soviétique. Deux poèmes dramatiques de Nicoleta Esinencu ("Fuck you Eu.ro.Pa», " $7 \mathrm{~km}$ ») interpellent d'entrée un père et une mère sur le mode pathétique. Ils remémorent une enfance heureuse dans un monde qui se délite. La vision de l'enfance suggérée en 
creux parce que contredite par ces enfants imparfaits rappelle la définition que Paul Thorez, fils du premier dignitaire communiste français de l'époque donnait-il y a presque quarante ans de cette classe d'âge. Ses «enfants modèles » à Artek, camp soviétique international pour pionniers d'élite sont la méritocratie à laquelle le héros des Lapins ne meurent pas ne parvient pas à accéder et que la protagoniste des drames de Nicoleta Esinencu semble profaner par sa seule existence.

Nous jouissions au camp de l'indépendance que tout enfant souhaite sans jamais la connaître (...). Nous étions les rois (...) Dans la société soviétique, l'enfant jouit d'une place privilégiée. C'est à lui qu'on songe en encourageant, soixante ans après la Révolution, le culte de la famille. L'enfant incarne l'avenir. Pour mieux le former, on lui propose un moule aussi attirant que possible: on lui propose des tâches, des responsabilités ou l'on fait semblant. On attend moins de lui l'obéissance que l'adhésion libre et joyeuse à l'ordre établi. On sait que lui seul en est capable. (Thorez, $1982: 46$ )

\section{A. Antigone des lettres moldaves}

Un entretien réalisé par Ileana Rusu en 2005 s'interroge sur le goût pour la boisson, les cigarettes, le café d'un «nom parmi les plus connus entre le Nistru et le Prut et sans doute au-delà des frontières de la République. ${ }^{5}$ (Rusu, 2005). Ce comportement est rapporté à l'éducation familiale ou l'hérédité puisque la journaliste mentionne que l'écrivaine est fille de Nicolae Esinencu (né en 1940) scénariste, aujourd'hui membre de l'Union des Écrivains de Moldavie et de Roumanie. Nicolae Esinencu qui a effectué ses études supérieures à l'Institut de Littérature «Maxime Gorki» de Moscou entre 1971 et 1973 est en outre membre de l'Union des cinéastes de Moldavie. Auteur de nombreux scénarios ${ }^{6}$, connu encore pour son excentricité ( teribilism») il s'intéresse à une forme d'art ayant pu orienter la prédilection de sa fille pour le théâtre. L'interview de septembre 2005 comporte l'échange de répliques suivant.

(Ileana Rusu) Les gens vous montrent du doigt. Vous êtes rebelle. Avez-vous souhaité personnellement être ainsi ou votre éducation familiale vous a-t-elle amenée à briser les clichés?

5 Voir «Nicoleta Esinencu. Copilul teribil al lui Esinencu» interview de Ileana Rusu, septembre 2005, $\mathrm{n}^{\circ} 17$, http://www.vipmagazin.md/profil/Nicoleta_ESINENCU/ page consultée le 9 septembre 2013. Tous passages en français sont traduits par Hélène Lenz.

6 Voir Nicolae Esinencu, http://ro.wikipedia.org/wiki/Nicolae_Esinencu. Dernière modification: 19 août 2013, page consultée le 9 septembre 2013. 
(Réponse Nicoleta Esinencu) J'ai peut-être hérité ce trait de mon père, rebelle et extravagant. Je ne désire pas être différente, j’ai seulement le désir de dire les choses tout haut. Il n'y a que deux solutions: dire ou ne pas dire. Moi, je veux appeler les choses par leur nom.

L'intempérance de langage de ses récits dramaturgiques serait liée à la violence sociale de l'après communisme. Le Septième Kafana écrit en collaboration avec Mihai Fusu et Dumitru Crudu a été élaboré sur un montage d'informations auprès des jeunes victimes d'un trafic de prostitution: «environ quinze personnes interviewées, avant de construire la pièce» qui a d'abord été montrée dans des villages. La naïveté des spectateurs, leur ignorance des codes dramatiques est invoquée comme un élément précieux de la communication artiste - public à l'état brut dans une Moldavie d'après l'URSS où la tradition théâtrale du $\mathrm{xx}^{\mathrm{e}}$ siècle - si elle a jamais existé en ces lieux - a été oubliée.

(Question Ileana Rusu): Où êtes-vous allés avec ce spectacle?»

(Réponse Nicoleta Esinencu): Nous avons eu la grande chance de tourner dans toute la Moldavie, dans beaucoup de villages. Dans beaucoup d'endroits, les gens n'avaient pas vu de théâtre depuis des dizaines d'années, ils n'avaient pas reçu de préparation adéquate. Mais il existait des clubs où les gens se rendaient le dimanche et c'est là que nous avons joué. Les gens achetaient des cornets de graines grillés qu'ils mangeaient pendant la représentation, ils parlaient durant le spectacle. (Rusu, 2005).

Le monologue dramatique $7 \mathrm{~km}$ - De Chisinău au Septième kilomètre remémore des souvenirs d'enfance et d'adolescence incluant la mention d'une précocité sexuelle incongrue ( «j'ai eu mon premier orgasme le jour où j'ai oublié à la maison mon fichu rouge»-Esinencu, 2011: 18). Auparavant, les vacances se déroulent au bord de la mer, à Odessa. Les parents sont aimants :

maman, j'ai peur l'eau / je criais (...) j'avais 2 ans / et la mer noire était bleue / j'avais 5 ans (...) les coquillages et les galets / ramassés sur la plage / pour que papa me fasse à la maison / un château de sable et de galets (Esinencu, 2011:185).

L'adolescence sera liée à l'achat, puis au culottage dans une machine à laver chargée de "beaucoup de cailloux» de jeans trempés au préalable dans le bleu de méthyle (Esinencu, 2011: 197-199). Ils symbolisent l'Amérique/ repoussoir montrée par la grand-mère, puis à l'école comme une menace permanente: "plus tard / on nous a dit à l'école / que cette Amérique-là est une grosse bombe atomique dirigée vers nous» (Esinencu, 2011: 188). Les jeans sont achetés en contrebande à des marins étrangers qui en trafiquent pour 200 roubles. Vasile Ernu montrera à son tour dans le récit: Prima mea 
pereche de djinsi / Ma première paire de jeans (Ernu, 2013:15) les spéculations d'un frère aîné enrôlé dans l'armée en 1980. C'est en Afghanistan, «ce pauvre pays oublié de Dieu» où ils font la guerre que les soldats russes acquièrent des produits introuvables chez eux (lunettes de soleil, appareil à cassettes Sony) «mais rien n'est plus désiré et respecté que la paire de jeans». Elle permet au narrateur de s'égaler aux enfants d'apparatchiks, de cosmopolites, de spéculateurs. Démobilisé, le frère entre à son tour dans la «catégorie respectée des 'blatnoï” trafiquants. À Odessa où se tient le «talciok» marché noir de la rue Malaia Arnauțkaia mentionné aussi par $7 \mathrm{~km}$ il achètera pour lui-même une nouvelle paire de jeans (Ernu, 2013, 15-18), (Esinencu, 2011 : 187).

Le départ à la mer coïncide avec les souvenirs d'un train spécial avec salle de projection. Le dessin animé n'est pas celui que mentionne Vasile Ernu quand il énumère les créations pour enfants d'URSS - de Habarnam à Nu Pogodi / Le loup et le lapin (version soviétique aujourd'hui censurée de Tom et Jerry) - (Ernu, 2013 :26-35). Mais il est certain que l'autorisation parentale est l'indice d'une éducation choisie.

À la mer, tu pouvais y aller avec le train jaune/ chișinău-odessa (...) nous le train c'était ce qu'on préférait/ parce que le train jaune avait une voiture vidéo/ c'était une voiture aux rideaux tirés/ avec un téléviseur et un magnéto / et j'avais le droit d'y aller moi aussi / mais seulement pour / tom et jerry (Esinencu, 2011: 189).

Fuck you apostrophe un père distant à qui s'adresser suivant des codes: ici un lexique médical énumérant des maux surtout féminins. Le poème $7 \mathrm{~km}$ montre ce père en possible dissident: il voyage en avion jusqu'en Georgie pour y retrouver «un vieil ami de l'époque des études à Moscou» qui disparaîtra. Le métier paternel, la question de sa transmissibilité crée les conditions d'une sorte de complexe d'Antigone désireuse d'exprimer, communiquer, commenter une réalité informe mais dangereuse en évitant les canons usés des auteurs moldaves des années cinquante. «Papa, ceci est un essai / Oui / Un essai. / Ne crois pas que je me suis mise à écrire. / Non! / Je ne veux pas devenir comme le poète-patriote Grigore Vieru» (Esinencu, 2006:16) Le sexisme des appels d'offres officiels à la création est récusé aussi: la Moldavie est infantilisée jusqu'à lancer des concours littéraire pour mères de trois enfants.

Papa, ceci est un essai pour un concours lancé par le Club des jeunes premiers ministres / Que m’a donné mon pays et comment je l'ai remercié? Papa, je ne participerai pas à ce concours. Je ne corresponds pas aux critères. (Esinencu, 2006:17). 
La narratrice montre en conclusion qu'elle "est la troisième", qu'elle a "deux frères aînés». Le père distant pousse-t-il l'insensibilité jusqu'à la confondre avec sa propre mère? Désignée dans $7 \mathrm{~km}$ comme roumaine, elle transmet à sa fille l'alphabet latin blâmé par la mère ukrainienne du père qui ne comprend que le cyrillique. La cécité paternelle, revers de la célébrité, est désignée à deux reprises comme de la banale grossièreté. Un an après le terrible tremblement de terre en Arménie «tu m'as frappée pour la première fois et en fait pour la dernière». La veille du jour où on a appris que l'Union Soviétique "n'existait plus»: "Papa est rentré ivre comme d'habitude. Il a baisé maman toute la nuit» (Esinencu, 2006: 20). Au-delà du renvoi à l'inexistence d'un code familial d'éducation des filles, le texte reprend un modèle littéraire du reproche filial: La lettre au pèrede Kafka, comme le rappelle Mirella Patureau, préfacière et traductrice de Fuck you. «Papa, il faut que je te dise quelque chose... Adipsie/ Aérophobie,/ Anémie,/ Cyphose, / Cystitye, / Cholécystite (...), (Esinencu, 2006 :15). Le monologue s'achève sur une litanie de remèdes. Comme dans l'ouverture nommant des maladies, ils sont énumérés dans l'ordre de l'alphabet latin: de $\mathrm{A}$ à $\mathrm{S}$ en introduction, de $\mathrm{A}$ à $\mathrm{V}$ en conclusion. Le monologue dramaturgique boucle donc par une liste de médicaments une liste de nostalgie, souvenirs, erreurs morbides sans doute psychanalysables - dans un pays où la psychanalyse ne serait pas interdite -. L'auteure suggère-t-elle que le théâtre est cathartique? Dans une société réduite à la misère, cette catharsis serait moins un noble rappel de l'Antiquité que la seule forme possible de thérapie mentale. Il est possible aussi que le texte tourne en dérision les post-modernes roumains. Le manifeste fracturiste de Marius Ianus décrit ces poètes dees années 1980 comme des baroques grotesques incapables de parler d'amour sans nommer des lobotomies. "papa, moi je suis pour le pays. Pour quel pays suis-je, moi? / Analgésiques,/ Antibiotiques/ Antiseptiques/, Anesthésiques/ Calmants / Contraceptifs / (...) (Esinencu, 2006: 35, 36). Bien avant, la patrie moldave a été montrée comme un lieu de tensions ethniques où «tous naissent en Roméo et Juliette», où "on n'imagine pas la vie sans souffrance», où «tout fait mal / La tête. / La gorge / L'estomac. / Le cœur / L'appendice / Les reins. / Les poumons.» (Esinencu, $2006: 24$ ).

Fuck you adopte la forme d'une confession publique ou d'une autocritique. Le récit décousu égrenant des souvenirs en contraste avec l'horreur présente est rythmé par une répétition: "Papa, il faut que je te dise quelque chose» (Esinencu, 2006: 15, 16, 20, 22, 24, 25, 27, 29, 31, 32, 34). La sensibilité du lecteur est sollicitée par des ressorts émotifs élémentaires: rappel de fautes 
enfantines vénielles, anticipation de l'obsession - le rêve d'Europe - dont les Moldaves sont écartés alors qu'ils sont les moins cyniques.

Je piquais chaque mois vingt-cinq roubles dans ta poche, papa / je ne sais pas ce que je faisais de cet argent, / Mais je gardais toujours sept roubles pour ma rencontre avec l'Europe!/ Je voulais tant la connaître. / C'était une sorte d'American Dream./ En réalité, l'Amérique me faisait peur.» (Esinencu, 2006:19).

Le loyalisme face à l'identité roumaine est-il le sentiment spontané, naturel et pur floué par le matérialisme d'en face?

Les enfants ne sont pas comme les adultes, papa (...) quand mon pays a voulu faire un pont de fleurs avec la Roumanie, moi j'y suis allée avec des fleurs, les autres y sont venus avec des télés, des frigos, des fers à repasser" (Esinencu, 2006: 21).

La dérision vise-t-elle les seuls Roumains, un sentimentalisme slave atavique à éliminer en soi ? "Grand-mère était une communiste ukrainienne, grosse et bête. La nuit du réveillon (...) On entendait des pétards. C’était la fête. «Les Roumains viennent reprendre leur terre» dit-elle puis elle ferma les yeux pour toujours» (Esinencu, 2006:21). L'adolescence est marquée par le début d'un vice associé à l'image des Russes et au chaos politique. «À quatorze ans, je buvais le vin au goulot./ Je vomissais et j'en buvais encore./ Dans mon nouveau pays la guerre a commencé.» (Esinencu, 2006:21). L'actualité journalistique à son tour est remplie de nouvelles effroyables ne pouvant que justifier le retour d'une dictature: "Je ne lis plus les journaux, papa : "Un petit-fils de quatorze ans a baisé sa grand-mère de quatre-vingts ans / Un père a tué son fils en le frappant à la tête avec une hache. / Des suicides en série. Un neuvième cas de suicide cette semaine. Une jeune fille de quatorze ans s'est jetée du septième étage. Sur sa poitrine était écrit: «tATu ! »avec du rouge à lèvres (Note de bas de page: groupe féminin de rock russe, tendance gay).» (Esinencu, 2006:30).

La pièce Sans sucre fait intervenir deux personnages : le «je » dramaturgique de Fuck you et un frère dénonciateur de l'immoralité familiale. L'attitude du garçon est interprétable à son tour comme un effet pervers du dégel de l'URSS «compensé» en Moldavie par la victoire de Voronine, président de la République de 2001 à 2009, chef du Parti des Communistes Moldaves et membre de la minorité russe (œuvrant comme tel pour une falsification des chiffres de la majorité roumaine: $75 \%$ selon le dernier recensement). ${ }^{7} \mathrm{Ce}$

7 Voir l'article «Vladimir Voronin», http://fr.wikipedia.org.wiki/Vladimir_Voronin, dernière modification: 19 mai 2013. Page consultée le 8 novembre 2013. 
frère réincarne de toute évidence le mythe de Pavlik Morozov, commenté aussi par Paul Thorez, par Vasile Ernu, par Savatie Bastovoï (Bastovoi, 2007: 30) et dont le philosophe Lucian Boia rappelle la raison d'être sous le communisme.

Aux enfants, on recommandait le récit très édifiant de V. Goubarev Pavlik Morozov (1950) où il était question d'un garçon de treize ans qui avait dénoncé à la police secrète son père 'contre-révolutionnaire' commençant ainsi sa carrière d'homme nouveau. C'était la plus dure attaque jamais imaginée contre les liens et les sentiments familiaux traditionnels. L'homme nouveau n'écoute plus la voix du sang, la voix de l'histoire lui suffit. (Boia, 2000: 151).

Dans les accusations stéréotypées réactualisées par le garçon avec une ignominie obscène, la sœur est une perverse abusant d'un frère plus jeune, les parents sont des petits bourgeois dégénérés, le frère aîné: un zombie de cinéma:

LE FRÈRE: À l'époque où / Ma sœur jouait avec la quéquette de Vova dans le sable, / Ma mère ne s'imaginait pas la vie sans un domestique avec des verres en cristal sur un plateau de porcelaine,/ Mon père se branlait, / Moi, je faisais des bonbons en caramel dans une cuillère/ Tandis que mon frère allait au Cinéma Patria de la rue Lénine. (Esinencu, $2008: 41$ )

La fin de $7 \mathrm{~km}$ montrera la destruction des paysages par la férocité du maintien politique russe dans une zone dévastée en proie aux derniers combats du communisme. Elle intègre aussi le dérèglement de la propagande face au capitalisme sauvage, l'expression de l'angoisse de se voir expulsé hors de chez soi.

La mer noire / n'est ni noire ni bleue / ni verte non plus / la mer noire a la couleur des terminaux pétroliers / La mer noire a la couleur des conduites de gaz et/ de la guerre en Géorgie / la mer noire a la couleur du trafic d'armes et de drogue en Transnistrie/ la couleur de la marchandise toxique de Chine (...)/ maman / j'ai peur la mer (Esinencu, 2011: 229).

Les contradictions engendrées par ces désordres mènent les plus sensibles ou les plus conscients à la folie. De même que la biographie autorisée de Savatie Bastovoï insiste sur une vocation littéraire et religieuse déclarée durant une hospitalisation en psychiatrie où il rédigera: Un Valium pour $\mathrm{Dieu}$, la fin de Sans sucre apporte la preuve du délire sacré de la sœur. Celleci bascule dans la maladie mentale pour cause d'injustice politique antiroumaine, sans doute compliquée de pressions incestueuses.

LE FRÈRE: Le jour où / Ma sœur a commencé à péter les plombs pour de bon/Moi, je ne me souvenais plus de ma mère/ mon père se branlait/ Et 
mon frère aîné faisait un recensement où nous étions déclarés minorité chez nous. (Esinencu, 2006:63).

De même que dans le cas de Savatie Bastovoï, l'épisode psychiatrique est la preuve paradoxale de la santé morale de l'héroïne. Dans une famille déréglée, elle seule dénonce brutalité et immoralité. Son indifférence aux évaluations politiques qui passionnent les garçons est saine, comme son ataraxie face à l'escalade de provocations sexuelles concomitantes de la libéralisation des mœurs. Enfant martyr de la politique autant qu' "enfant modèle» (sans en avoir l'apparence) fidèle à une éthique consacrant la spontanéité de l'artiste comme «juste», cette sœur est bien l'adolescente emblématique démontrant la dignité sociale d'un art montré comme aussi nécessaire à la collectivité que le travail ouvrier ou intellectuel savant.

\section{B. L'idiot dans sa forêt}

Les lapins ne meurent pas, roman de Savatie Bastovoï traduit en français par Laure Hinckel en 2013 avait déjà été publié en Roumanie en 2002 comme en témoigne le journaliste moldave Stelian Gombos, annonçant une édition corrigée augmentée de 2007 aux éditions Polirom (Iași).

- Vous êtes l'auteur d'un roman sur une enfance soviétique (...). Que suggère ce titre? - Ce roman écrit durant mes années d'études à Timișoara a été publié aussi à Brașov (éditions Aula, 2002) mais avec une circulation restreinte. L'empire y est vu à travers les yeux d'un enfant. Tout au long du livre, comme une toile d'araignée se tisse la récurrence d'une discussion absurde entre Lénine et Félix Edmundovitch: des débris de slogan y résonnent et ils sont transformés par l'esprit de l'enfant en fantasmes d'hérö̈sme ou de peur. À un moment donné, l'évidence de l'immortalité des lapins se révèle de même ordre que la continuation de l'Union Soviétique. Il existe des hommes pour croire encore que les lapins ne meurent pas. (Gombos/ Bastovoï, 2007: 7).

Le narrateur adopte donc le point de vue d'un préadolescent découvrant le monde avec fraîcheur. L'absence d'agilité intellectuelle de ce héros étonne, renvoyant le lecteur à ses qualités invisibles. La pureté de la vie intérieure de Sasha rappelle à coup sûr des modèles russes devenus universels : la crédulité mystique du Prince Muychkine dans un «Idiot» qui se déroulerait à la campagne, en seule compagnie de villageois et de camarades dont une cloison étanche: leur excellence scolaire et sa propre nullité, le séparent. L' "idiotie» dostoïevskienne de Sasha renvoie à une profondeur affective frustrée par un environnement brutal, à la rigidité d'un enseignement soviétique incapable de percevoir la nature des problèmes - spirituelle plus qu'intellectuelle - 
posés à une âme en formation. La simplicité des questions qui l'assaillent renvoie à une totale absence d'information cognitive ambiante contribuant au même résultat.

La solitude de Sasha dès qu'il échappe au cadre scolaire, son imagination lui font entendre en esprit des conversations idéales. L'école l'abreuve d'avanies dues à ses retards involontaires (il vit trop loin pour que l'autobus le dépose à l'heure), à une négligence corporelle que sa mère ne lui apprend pas à combattre, à ses mauvais résultats. "Les filles qui apprennent bien reçoivent des livres neufs» mais les cancres ont de vieux exemplaires. Dans le car qui le ramène chez lui, Sasha se dit un jour "qu'il en a marre de cette vie. Il ne supportait plus qu'on lui dise des méchancetés et il en avait marre aussi de leur école.» (Bastovoi, 2012:105). Il pourrait se rattraper en bricolant, lui conseille l'institutrice avec mépris. «Pourquoi ne pas fabriquer une règle en bois et la rapporter puisqu'il n'est bon à rien et ne récolte que des 'insatisfaisant en conduite'?» (Bastovoi, 2012: 82, 94). Les escapades du garçon en forêt constituent par compensation une forme d'école buissonnière durant laquelle il reconstitue les savoirs non acquis aux heures de cours. Lénine, dont le portrait orne la salle de classe, dont l'exemple est si présent dans le discours adulte que Sacha se demande presque à chaque geste «ce que Lénine aurait fait à sa place» (Bastovoi, 2012: 52) est l'acteur principal de dialogues imaginaires repensant le monde et le socialisme. Aurait-il pu arracher un noyer dans son enfance? (Bastovoi, 2012: 60). On confie à Sacha que Lénine aussi écrivait mal mais chez lui contrairement à Sasha, l'imperfection s'est déclarée tard. "Ce n'est qu'après avoir fait la Révolution et être resté en prison que son écriture s'est gâchée (...) car il devait écrire vite et beaucoup pour sauver les gens pauvres» (Bastovoi, 2012: 29). Sacha est un garnement qui «dessine des sottises», ce qui le rend indigne de devenir pionnier. Il promettra donc solennellement au portrait de son ange gardien d'y renoncer. Il apprendra par cœur des poèmes « récités dans sa tête parce qu'il savait que Lénine les entendait, comme Sasha l'avait rêvé dans son sommeil» (Bastovoi, 2012: 52). Vladimir Ilitch joue aussi un rôle dans un délire forestier invitant à couper du bois, faire du feu, «cueillir des champignons vénéneux pour les enfants d'Amérique: qu'ils les lavent bien avec du savon et n'envoient plus de bombe atomique sur les enfants d'Hiroshima.» Un lapin mort trouvé dans l'herbe sert de couvre-chef au penseur politique. «Regardez ces éclats que j'ai dans la tête, ce sont des éclats capitalistes.» (Bastovoi, 2012: 36, 37). Sacha a appris en effet en classe que "Lénine était bon, qu'il travaillait au coude à coude avec les ouvriers" des 
forêts notamment (Bastovoi, 2012:30). L'histoire de la Russie se constitue aussi en fonction du comportement des puissants face à son entourage: «le tsar était méchant, il avait fusillé le frère de Vladimir Ilitch.» (Bastovoi, 2012: 30). Lénine théoricien du quotidien ne dédaigne pas d'émailler son discours de fantaisies poétiques, d'allusions au dessin animé $\mathrm{Nu}$ Pogodi/ Le loup et le lapin dont des images ornent les couvertures de cahiers de filles.

«Il ne faut pas allumer de feux dans la forêt, car le lapin tire au pistolet et tape sur les piétons avec son échelle. Nous ferions mieux de cueillir fraises des bois et perce-neiges pour les mettre dans le réservoir à essence, que des fleurs poussent sur les roues!» (Bastovoi, 2012:37).

Il engage aussi avec son intime Felix Edmundovici un débat méthodologique burlesque. Il y est question de coq dont le modèle agit dans son subconscient pâte à modeler.

Le coq, si on lui arrache les plumes à sec et que les plumes, on les colle sur la pâte à modeler qui dans votre subconscient, comme vous l'avez rappelé vousmême existe, nous pouvons obtenir à la suite de ce transfert de plumes du coq vivant sur le coq en pâte à modeler de votre subconscient, comme j'ai dit, un autre coq sinon identique, du moins ressemblant. (Bastovoi, 2012:130).

En fin de roman, Vladimir Ilitch adoptera un nouveau partenaire de discussion: Makarîci qui lui donne la bonne réplique sur ses occupations lors de la Journée du Cosmonaute («j'étais devant le téléviseur, Vladimir Ilitch, pas dans le jardin»- Bastovoi, 2012:248) Makarîci ne coupe plus d'arbres depuis que Vladimir Ilitch l'en a convaincu et la constatation prélude à un exposé sur le rôle de l'oxygène dans le métabolisme humain, dans la forêt, dans la photosynthèse et tout ce qui vit (Bastovoi, 2012 :253). Dès le milieu du roman, Sasha qui regrette de n'être pas né du temps de Lénine va réajuster le discours de l'idéologue aux nécessités présentes. C'est l'écologie qui lui paraît requérir une vigilance politique maximum outre qu'elle s'intègre dans la discipline enseignée à l'école. "L'air doit être propre, mon cher. Ainsi nous porterons à maturité une génération d'hommes sains (...) - Vous dites que la forêt est belle, elle vous plaît? - Oui, c'est du très bon travail. - Chacun devrait faire de même: de l'ordre sur son lieu de travail» (Bastovoi, 2012:176). Le culte de Lénine est légitime parce qu'il a aidé les enfants et Sacha envisage en fin de roman de liquider ceux qui caricaturent le héros ou ignorent ses exploits.

Il en voulait à mort à celui qui avait fait des moustaches entortillées à Lénine. Il y en avait toujours un, genre Ciornîi, qui ne savait pas lire. Et ne savait même pas qui était Lénine. Papa lui a dit que ceux-là, on les appelle des débiles et que leurs papas sont des ivrognes. C’est pour ça qu'ils sont bêtes 
et ont les yeux troubles. Si un enfant comme ça savait qui était Lénine, ça lui ferait mal. Sacha le tuerait. (Bastovoi, 2012: 279).

Le passage à l'état de pionnier est le principal événement de l'enfancepréadolescence décrite par le roman. Sale, désordonné, mauvais élève, Sasha est parmi les derniers de sa classe à accéder à cette dignité (Bastovoi, 2012:119). Il imagine l'effet produit sur tous le jour où il sera enfin distingué.

Cela se saura plutôt par des voies détournées (...) On le regardera, on lui demandera: 'Alors Sacha, j'ai appris que tu vas devenir pionnier?' Et lui éclaterait de joie à l'intérieur. Il garderait son sérieux et ne montrerait rien (Bastovoi, 2012: 139).

Le foulard rouge, déjà présenté par Nicoleta Esinencu comme un sceau magique, une décoration dont il faut se montrer digne lui apparaît comme l'insigne sacré par excellence. Depuis longtemps les professeurs commentent sa couleur, marque du sacrifice communiste. "Vous pionniers, vous portez autour du cou un petit morceau du drapeau que les soldats soviétiques ont mouillé de leur sang pour que vous viviez aujourd'hui en paix.» (Bastovoi, 2012:38). Les élèves de la classe invitées à le porter rejoignent la galerie des portraits officiels. «Il regardait leurs foulards rouges que soulevait le vent et qui flottaient comme il avait vu chez les pionniers partisans peints sur les tableaux de la grande école et dans les livres.» (Bastovoi, 2012:52). L’insigne prête à ceux qui l'ont mérité une élégance de chaque instant. Quand les pionniers sont dans le car, en route vers leur domicile, à peine «sortent-ils la tête par la fenêtre que les foulards rouges flottent dans le vent. " (Bastovoi, 2012:54). Le jour où Sasha est intronisé, sa toilette prend davantage de temps, il répète avec soin le serment à prononcer et se prépare pour la cérémonie qui verra "un grand de $\mathrm{VI}^{\mathrm{e}}$ nommé Andrei nouer son foulard» pour sa plus grande déception car il aurait aimé que le geste soit accompli par une fille (Bastovoi, 2012: 151, 152). Mais auparavant, l'instrument de son changement d'état l'a fait rêver tel un accessoire sacerdotal. «Il pensa à son foulard dans son cartable et qu'au retour, il sortirait la tête par la vitre baissée pour que le tissu rouge flotte au vent (...) Il était si joliment plié dans son cahier. Rouge et bien repassé.» (Bastovoi, 2012:145). Le rituel lié à l'insigne est décrit aussi par Vasile Ernu dans Pionieri forever/ Pionniers forever. Des punitions susceptibles d'affecter les négligents, les insolents, les maladroits incapables de la tenue réglementaire sont mentionnées.

Nos premiers jours en cravate de pionnier se passaient plutôt bien. Elle nous plaisait en effet. Le matin, nos mères la repassaient avec soin, plus tard nous le ferions nous-mêmes, puis il fallait réaliser un nœud parfait. Réaliser un nœud parfait: voilà du grand art. Des roublards nouaient la cravate en style 
' cow-boy'. Mais ce geste était sanctionné. Puis peu à peu, nous oubliions l'accessoire à la maison, dans un coin de salle de sport, dans un sac, roulée en boule dans des poches. À nouveau les sanctions pleuvaient. Le pionnier respecte des règles, il doit être un modèle de comportement. (Ernu, 2012:12).

Dans une provocation comique évidente, Nicoleta Esinencu associe un cliché verbal de l'Empire communiste (où le sexe n'aurait pas existé puisqu'il s'agit d'une invention capitaliste) avec un acte manqué générateur d'indécence. La confusion des effets et causes souligne la valeur de consécration de l'insigne et les possibilités de transgression attachées au fait de ne pas le porter.

Non papa, en Union Soviétique, le sexe n'existait pas! Une sorte de menstruation continue. / j'ai eu mon premier orgasme le jour où j'ai oublié à la maison mon fichu rouge./ L'institutrice essayait de m'expliquer que mon acte n'était pas digne du comportement d'un pionnier communiste (...)./ J'étais au premier rang de la classe. / Debout. / (...) Plus tard, j'ai appris que lorsqu'on veut faire quelque chose d'indigne d'un pionnier communiste, il suffit d'enlever son fichu rouge. Tu n'as pas de fichu, tu n'es pas pionnier. (Esinencu, 2006:17-18).

La nouvelle «La clé» de Mircea Sâtimbreanu (1926-1999) écrivain roumain pour enfants montre un garçon emporté par son premier foulard dans une rêverie d'apesanteur angélique que seule une sensation de puissance empêche de confondre avec l'extase séraphique d'un premier communiant ou d'un saint conscient de son aptitude aux miracles.

Mihaiță était pionnier depuis quelques heures quand il sentit sur son cœur comme un battement d'aile, la première palpitation de sa cravate rouge (...) Tout étourdi, il rentrait à présent à la maison. La joie lui donnait l'impression de ne plus être le même frêle gringalet mais bien un autre: à la fois plus puissant et indiciblement léger. Sinon, comment le petit vent qui agitait amicalement la soie de sa cravate aurait-il pu l'élever au-dessus des rues, des maisons, jusqu'aux nuages? Les passants lui souriaient, les inconnus l'appelaient par son nom mais surtout Mihaiță sentait un pouvoir inconnu animer tout son être comme si lui, petit homme de sept ans était non seulement prêt à des exploits de géant mais comme s'il en était devenu capable. Qu'il fasse un seul signe et ce bloc inachevé se dresserait jusqu'au ciel en un instant avec tous ses étages! Ou qu'il tende la main et ce camion serait déchargé... (Sântimbreanu, 2011: 67).

La meilleure preuve de l'angélisme obligatoire du pionnier est communiquée par une anecdote des Lapins ne meurent pas. Comme une scène du roman de Paul Thorez fustigeant le hooliganisme d'un garçon qui a joué à uriner «en arc-en-ciel» devant témoins, elle montre le jugement public de deux coupables de flirt ou de rapport sexuel. Ils sont injuriés 
devant tous par les éducateurs qui obligent les élèves à former le carré pour assister à leur dégradation "A quoi peut bien te servir de venir à l'école? Marie-toi et file au kolkhose!» (Bastovoi, 2012:69).

Ils ne méritent pas de porter cette infime partie du drapeau de la Patrie (...) Ils ont outragé le foulard de pionnier. Honte à eux parce qu'ils ont craché dans le sang de ceux qui leur ont sauvé la vie et sont morts pour qu'aujourd'hui, ils vivent en paix (...) Ils ont foulé aux pieds leur serment prononcé devant la Patrie: être des pionniers exemplaires suivis par les plus petits, les octobriers qui entreront aussi dans les rangs des pionniers. (Bastovoi, 2012: 66, 67).

L'obtention du grade de pionnier, le statut auquel il donne droit est la ratification d'une initiation d'abord politique (le premier pionnier fut Pavlik Morozov, renégat de ses parents), ensuite morale. Établie sur une base de chasteté, cette initiation éthique communiste se révèle plus proche des choix chrétiens orthodoxes exprimés aujourd'hui par le moine Savatie Bastovoi que de l'amoralisme imité de l'Occident capitaliste. Ainsi l'écrivain communique au journaliste Stelian Gombos ses positions en matière de moralité comportementale et sexuelle. Il conclut par la nécessité de revaloriser la religion pour suppléer au nouveau manque de coercition législative face à des actes où il continue de voir des délits:

Nous sommes dans une époque difficile, une époque de liberté où chacun peut agir à son gré. Celui qui veut faire le bien y sera autorisé mais celui qui voudra faire le mal n'en sera pas empêché: il le fera. Il y avait autrefois des lois pour l'en dissuader (...) Aujourd'hui, on peut se livrer à des actes qui vous envoyaient naguère en prison (note de l'auteur: ainsi l'avortement, l'homosexualité, la pédophilie.) En République de Moldavie, la limite d'âge pour des relations sexuelles librement consenties a été abaissée de 16 à 13 ans $(\ldots)$ de sorte que nous sommes confrontés à la situation évoquée par les Saintes Écritures dans l'Apocalypse: 'Qui veut se perdre, qu'il se perde, qui veut se sauver, qu'il se sauve!' Car Dieu nous aide à distinguer la voie dans laquelle nous sommes engagés, veillant sur notre liberté. (Gombos / Bastovoi, 2007:20)

Le glissement de la consécration politique citoyenne du pionnier à un état de consécration religieuse contiendra donc une très faible part de paradoxe. Le communisme athée interdit de croire en l'existence de Dieu. Lénine athée a soutenu une civilisation soviétique exploratrice du cosmos et obtenu la preuve - grâce au cosmonaute Gagarine - que le ciel est vide, comme en est convaincu Sasha au début du roman pour les mêmes raisons. Adonné au culte de Lénine, Sasha vit l'idéologie comme un dogme. C'est de ce dogme, enseigné aussi par son propre père que l'écrivain Savatie Bastovoi 
a dû s'éloigner, dans un refus de l'autorité paternelle précisément commandé par un statut de pionnier fidèle au reniement du père par Pavlik Morozov. Le père de l'écrivain est en effet montré comme un accusateur fanatique des prêtres locaux.

Stefan Bastovoï n'a que deux ans lorsque son père le met en selle. Il s'habitue dès lors à voir le monde depuis la hauteur d'un cavalier de l'athéisme scientifique qui on ne manque pas une occasion de donner une leçon anticléricale. Chaque fois qu'ils croisaient sur leur chemin des prêtres ou des moines, le père arrêtait son cheval et les montrant du doigt avec mépris, lui disait: "Regarde les bandits en jupe qui ont brûlé sur un bûcher Giordano Bruno!» (Gombos, Bastovoi, $2007: 2$ ).

La conviction sauvagement inculquée sera responsable d'une fureur de Sasha dans le roman. Toutefois Sasha - à l'inverse du marmot endoctriné identifie correctement les meurtriers de Giordano Bruno: des Occidentaux, si bien que sa colère prend le tour à la fois autorisé et enchanteur d'une volonté de vengeance contre l'Ouest capitaliste.

Le soleil tapait si fort qu'il se souvint du bûcher où avait brûlé l'homme qui avait soutenu que la Terre tourne (...). Il se dit que rien n'était pire que d'être brûlé vif. Il se sentait soudain si furieux contre les capitalistes qu'il imagina de les mettre nus, de les coucher sur des tessons de bouteille et aussi de leur donner des coups de marteau sur la tête. La pensée le troubla tout en le ravissant et il frappa plus fort la bouteille cassée. Et s'il leur mettait les doigts sur les bouts de verre... Leur planter du verre dans les yeux lui sembla la meilleure idée. (Bastovoï, 2012: 223)

La biographie de Savatie Bastovoï publiée sur son propre site web insiste sur des traumatismes privés l'ayant conduit à la vie monastique. Sa plongée dans la foi n'a pas renié d'entrée l'influence paternelle puisque à l'instar de son père enseignant de marxisme, il avait projeté de s'orienter vers la philosophie (étudiée à l'Université de Timisoara) avant son entrée en religion. L'interview Savatie Baştovoi, postmodernismul în rasa călugărească/Savatie Bastovoï, le postmodernisme en soutane qui interroge l'écrivain sur les rapports de l'orthodoxie avec la modernité renoue avec la question emblématique de la rotation de la terre, de l'héliocentrisme. Comme dans le cas de la moralité sexuelle, "la vision orthodoxe authentiquement chrétienne sur le monde et la science» s'opposera moins aux positions communistes rationalistes pro-scientifiques qu'à la dogmatique des romano-catholiques et protestants, montrée comme responsable des crimes de l'Inquisition.

Il n'y a pas de contradiction entre l'Orthodoxie et le développement technique. Il convient ici d'user du terme 'Orthodoxie', non du terme 
'christianisme' étant donné que le combat contre la science est une affaire de romano-catholiques et de protestants, lesquels se nomment aussi chrétiens. Les Orthodoxes n'ont jamais brûlé un homme sur un bûcher parce qu'il croyait que la Terre tourne. Si la dogmatique des romano-catholiques et des protestants les a mis en situation de nier la science, c'est que les découvertes scientifiques contredisaient leur vision du monde et de l'homme. Mais pour ce qui nous concerne, la science confirme les dogmes orthodoxes. (Târziu/ Bastovoï, 2007).

Cette ambiguïté face aux leçons des adultes est réverbérée par les méditations de Sacha en forêt (La terre tourne-t-elle?) mais aussi par sa rêverie iconographique ou son délire montrant une enfant (Sophie) sur les épaules de son père. Pareille à l'enfant Jésus sur l'épaule de SaintChristophe, la fillette avance portée par l'homme au-dessus de la ligne de flottaison des blés ou des fleurs éclatantes, dans un champ lumineux aussi grand que le monde, disque infini éclairé par un soleil orange à l'extrémité duquel on bascule, tout à la fin du roman - «de l'autre côté». C'est-à-dire dans la nuit, l'hiver, peut-être le monde folklorique roumain des «Blajini»: «les Bénins, les Doux, les Bienheureux» transparents qui sont les âmes des morts continuant d'exister sous une terre plate. Cette vision poétique obsessionnelle traverse le roman sans explication narrative plausible (les passages montrant Sophie sur les épaules de son père dans la lumière d'or sont notés en italiques) et elle équivaut peut-être à un rêve christique? ou féministe? de Sasha consacrant son admiration pour la terre russe - la plus grande du monde, ne voyant jamais le soleil se coucher -. On peut penser aussi que cette rêverie iconographique para-chrétienne, pré-chrétienne ou simplement proche de la perfection esthétique telle que Sacha la rêve compense son ignorance des mythes, des contes, de toute forme de soutien familial apporté à son besoin d'enracinement dans une croyance populaire au sens étymologique du terme.

Son père, un homme cultivé diplômé de l'École de Philosophie de Léningrad connaissait la Bible et les Saintes Écritures mieux que les prêtres de son temps en raison des exigences de son statut de propagandiste de l'athéisme. Il avait pour mission d'aller dans les brigades, les kolkhoses pour combattre avec des arguments darwinistes, idéologiques ou séculiers la croyance en Dieu et dans les vérités chrétiennes. Parfois il emmenait Stefan auxquels il inoculait ses convictions athées de sorte que l'enfant grandissait en réfléchissant sur le mensonge, la perfidie, le fanatisme, le crime des serviteurs de l'Église et sur l'ignorance des hommes du peuple qui n'ont jamais lu Marx, Hegel, Kant ou Lénine. (Gombos / Bastovoi, 2007 :2). 
Contrairement à ce père pourfendeur de la médiocrité intellectuelle générale, le Lénine des discussions avec Felix Edmundovici apparaît plus comme un imbécile fraternisant dans la joie avec les truismes que comme un logicien de haute volée. C'est cette simplicité qui va droit au cœur du héros, motive à la fois son désir de s'améliorer et son affection pour l'homme politique à l'esprit sans artifice. Face aux méditations élémentaires de l'attachant Sacha, le lecteur est vite gagné à son tour par un besoin de quiétude et de rabâchage. Comme le protagoniste, il se sent incapable de maîtriser les règles de fonctionnement d'une société sans repères apparents, morale explicite ni discours. Il en vient comme l'auteur et son héros à reconnaitre le caractère rassurant de la propagande, d'une discipline quasimilitaire, à adopter comme l'enfant le parti de l'indifférence politique, à découvrir dans le plus menu fait au cœur de l'endoctrinement l'essence de l'existence. Il établit par conséquent entre infantilisation et esprit sacré d'enfance des liens communiquant la clé de l'impression de sagesse, d'humilité quasi spirituelle produite par ces récits moins nostalgiques du communisme que du statu quo d'une paix apolitique, mystique vue comme seule condition du développement humain.

\section{Dumitru Crudu: le thriller social et politique linguistique}

En février 2013, Dumitru Crudu a publié à Bucarest: Un American la Chișinău/ Un Américain à Chişinău et le roman a été désigné comme le meilleur de sa carrière (Borzin, 2013), (Pilchin, 2013). La notice bibliographique de l'ouvrage découpe en trois catégories les publications de cet auteur né en 1968. Poète novateur, il a fondé en 1998 aux côtés de Marius Ianus le mouvement fracturiste par manifeste publié dans Monitorul de Brașov/ Le Moniteur de Braşov. Il a publié cinq volumes poétiques dont le dernier a pour titre: Eșarfe în cer/ Écharpes dans le ciel (Editura Cartier, Chișinău, 2012). Il a aussi écrit du théâtre. Le prix UNITER 2003 lui a été décerné en 2003 pour la meilleure pièce de l'année en Roumanie. Ses œuvres jouées en République de Moldavie, Roumanie, Allemagne, Italie, France, Haïti, Cameroun, Bulgarie ont été transposées en films en Italie, Roumanie, République de Moldavie. Enfin, Un Américain à Chișinău est son troisième roman publié après Măcel în Georgia/ Massacre en Géorgie édité à Iași par Polirom en 2008 et Oamenii în Chișinău/Les hommes de Chişinău paru à Bucarest en 2011. Des fragments de récits de Dumitru Crudu sont traduits en tchèque, allemand, anglais. 


\section{A. Intrigue et rythme «plébéiens » d'un romancier efficace}

La critique souligne le rythme irrésistible du dernier livre de Dumitru Crudu, son suspense, sa narration "trépidante aux virages spectaculaires bien contrôlés». La nature des événements rapportés concourt au vertige produit par les phrases. Quoique poète et dramaturge, l'écrivain n'est pas «un adepte de l'hybridation des genres». À l'inverse «il vise à les purifier» (Cernat/ Crudu: 2013). «La poésie doit redevenir poésie, le théâtre théâtre et la prose: prose» même si des scènes du roman sont «construites avec une minutie de metteur en scène." Le "rythme fulminant» qui impose le texte comme romanesque ôte de la vraisemblance aux tribulations des personnages. Anton Șleahitșchi, journaliste bessarabien installé en Roumanie depuis ses études à Brașov va revenir à Chișinău en compagnie d'un Américain désireux de connaître la patrie d'origine de cet ami de rencontre. Entre Roumanie et Moldavie, les connaissances d'Anton tissent un réseau de survie, de combines, de patriotisme. Les pérégrinations du héros dans les rues, les cafés, les transports publics, les salles de rédaction, les bureaux de postes, les groupes scolaires lui font croiser des littérateurs, de belles ex-étudiantes à la recherche de sponsors pour leurs diplômes de haut niveau sans débouchés, des paysans revenus à «l'arriération" comme surnaturelle des villages derrière le Prut, des bons, des méchants et une grande quantité de gens louches. Cette toile de fond urbaine et campagnarde va voir se développer en contrepoint la tragédie de Lora, victime d'un jaloux maffieux qui la punit finalement d'avoir osé rêver d'une expatriation.

Paradoxalement, la cadence narrative diminue «le plaisir du texte» considère la critique. Le lecteur est ici renvoyé à une propriété du style de Dumitru Crudu ( « une écriture abrupte») sinon à sa théorie «fracturiste» des années 1990. Le «réalisme du roman est traditionnel » considère pourtant en avant-propos Liviu Antonesei. Il exploite en partie «le filon biographique», décrit des péripéties calquées sur des expériences vécues par l'auteur, ancien étudiant à Braşov comme son héros. Les «raccourcis rapprochent le texte du roman populaire», la rapidité narrative procède d'une vitesse d'écriture laissant aussi paraître des « défauts de finissage». Quant à l'intrigue, c'est une «story robuste, dynamique, aux traits cinématographiques marqués» selon une recension citée par le blog de l'écrivain. Ce «roman 'plébéien' plein de vie comporte aussi une dimension sociale, identitaire complexe apportant un vent de fraîcheur dans une prose bessarabienne récente marquée trop souvent par le narcissisme et le manque de souffle.» (Crudu, 2013). 
Le roman de Dumitru Crudu semble d'abord user des effets attractifs d'une "pornographie» soft que ne renierait pas le Philip Roth du "Complexe de Portnoy», de "Good-bye Columbus». D'entrée, deux des beautés de l'aventure aperçues naguère par le timide Anton en Faculté de Philologie s'embrassent sur la bouche à une table de café avec l'approbation tacite d'un public d'amies qui fument et consomment. Cette provocation d'ouverture n'a rien de gratuit comme le montrera la suite du roman. Elle est même puissamment motivée par le fond de violence de la relation entre les sexes: un trait de mœurs jadis bridé et qui depuis la chute du communisme se donne sans doute désormais libre cours. Très vite, les péripéties vécues ne sont plus seulement celles d'Anton, l'apprenti écrivain moldave venu étudier et publier en Roumanie mais celles de Martin, marginal venu d'Amérique pour se documenter sur la vie d'après l'URSS. Les projets de Martin sont assez vagues pour inclure dans son "voyage d'étude» la séduction de Roumaines et Moldaves. Lora, amante d'Anton avant de devenir la victime du roman tombera dans les bras de Martin. C'est pourquoi sans doute elle disparaît avant d'être retrouvée atrocement mutilée pour des raisons que n'éclaircissent pas vraiment les dernières pages. La problématique de ce roman d'aventures quasi policier rejoint donc celle du "septième Kafana" de Nicoleta Esinencu dont Dumitru Crudu fut l'un des trois signataires. Elle reprend un thème de "Profil bas" de Paul Goma (traduction française de 2001) les effets de la chute de l'empire soviétique sur une pègre abusant de la crédulité de jeunes femmes, sur place ou à l'étranger. Le motif relève de ceux dont des régimes répressifs du passé usèrent en vue de justifier l'interdiction de toute libération sexuelle féminine. Il équivaut peut-être à la question de la «traite des blanches» sur laquelle la romancière diplomate roumaine des années 1930 Hélène Vacaresco, était déjà officiellement invitée à se pencher dans ses discours de la Société des Nations. D'autres motifs relevant de la criminalité internationale: trafic de drogue, délinquance enfantine, dégradation des mours concomitante de l'afflux de réfugiés en Europe occidentale ont été liés par la vie politique occidentale des années 1930 à ce problème de la «traite des blanches» montré comme récurrent. La menace qu'ils représentent fait aussi partie de l'atmosphère du roman. La paupérisation moldave encore aggravée par la chute de l'URSS est montrée en quelques pages, de même qu'elle a été mentionnée par Nicoleta Esinencu. Les villageois bessarabiens sont réduits à une quasi-mendicité par la chute du géant soviétique auquel ils avaient été inféodés. Ils se nourrissent désormais grâce à des colis reçus à la poste (Crudu, 2013: 244-245). La Moldavie du roman est aussi la zone à risques exigeant une protection de l'Américain. 
Tu lui as dit que je l'accompagnerai à Chisinău sans me consulter? - Oui, et je te demande de ne pas me le refuser. Ma femme vient d'accoucher, je dois rester près d'elle. - Alors, il n'a qu'à y aller seul. - La Moldavie est un pays très dangereux, où les gens sont dévalisés, tués en pleine rue, je ne veux pas courir ce risque. C'est le pays des trafiquants d'êtres humains, des vendeurs de reins. C'est le pays du racket et je veux que ce pays arrive sain et sauf à Chișinău. Fais ça pour moi, please! (Crudu, 2013:187).

Comme le précise Dumitru Crudu en interview, Anton Sleahistchi a conscience d'être confronté où qu'il aille à l'image effroyablement dégradée de son pays. Sa «Moldavie d'au-delà du Prut est devenue (...) un Afghanistan aux portes de l'Europe, un triangle des Bermudes dont on ne peut revenir.» (Pilchin, 2013).

L'Américain est-il enclin à séduire des Moldaves pour les sauver de la misère et la violence? Si la réglementation socialiste voyait l'intention de mariage de ressortissants locaux avec des titulaires de passeports occidentaux comme quasi-criminelle, dans le contexte littéraire roumain, le drame de la séduction par des étrangers possède une résonance mythique liée au passé ottoman, durant lequel furent remis en honneur les récits légendaires de rapts par des pirates. La ballade balkanique Chira-Chiralina qui a inspiré Panaït Istrati narre un enlèvement de jeune fille par un Turc manœuvrant son désir de luxe et d'évasion. On peut considérer que Dumitru Crudu utilise ce cliché ancien et son canevas, plaçant dans la lumière de l'actualité un drame déjà revisité par la législation communiste soviétique. Si le «vol», le rapt de belles filles par un étranger est moralement blâmable, c'est qu'il dérange le fragile système des séductions autochtones. Il peut par conséquent transformer en tragédie sanglante une aventure automatiquement régulée par la misogynie ordinaire de la vie sociale entre co-nationaux: associant le mépris envers la femme à la permissivité érotique dont tout amateur masculin peut de fait profiter. Soulignant en interview que son roman est un livre sur les $a$ priori «qui font naître mépris et haine de soi» Dumitru Crudu affirme qu'il a «introduit aussi dans son livre les préjugés entre hommes et femmes, de sorte qu'Un American à Chişinău est aussi un roman sur les milliers de préjugés qui nous empêchent de nous voir nous-mêmes sous notre jour véritable.» (Dumitrache, 2013).

\section{B. Roumanité / russité: une actualité moldave changée en Histoire}

Nombreux sont les détails concrets et anecdotes sur la Moldavie, les Moldaves d'après 1992 dans cet Américain à Chișinău chargé donc de traiter 
des stéréotypes conçus par «des Roumains sur d'autres Roumains ou de ceux des Bessarabiens envers eux-mêmes " (Dumitrache, 2013). L'intrigue se déroule dans des villes de Roumanie et dans le petit pays du héros qui doit se faire établir un nouveau passeport. Anton vivant à Brașov a en effet envoyé sa pièce d'identité valser aux orties. Son séjour en Moldavie le confronte à des brutalités policières (on le prend pour un Roumain) qui rendent indispensable le sauf-conduit l'autorisant à revenir. Son lieu de naissance lui paraît désormais en effet pire que la Sibérie "où d'ailleurs son grand-père Gorita a été déporté en 1953 pour s'être exclamé au décès de Staline: c'est un chien qui est mort!» (Crudu, 2013: 253).

Maintes tribulations des personnages sont liées aux effets de leur nationalité sur les Roumains de rencontre, à leurs difficultés de communication, leur infériorité économique d'ex-Soviétiques, à l'hostilité qu'ils suscitent, en bref à la description circonstanciée du complexe de leur différence durant la période dite post-décembristequi a confronté des locuteurs de même langue enrôlés par l'Histoire dans des camps opposés. La situation présente faisant circuler d'un pays à l'autre Bessarabiens et Roumains déplacés par les fluctuations politiques - n'est pas nouvelle. Dès 1918 quand la Bessarabie est passée sous contrôle roumain, après 1941, 1945 des centaines de milliers de réfugiés ont tout abandonné pour «fuir les Russes» et s'installer plus à l'Ouest du territoire roumain sans parvenir à croire que le communisme les rattraperait. Cultivent-ils la nostalgie fleur bleue du sol jamais vu ni foulé, susceptible de les fournir en reliques de l'origine? Est-ce une simple idée de poète?

Anton ne but rien contrairement à Matei Rusu qui lui réclama un sachet rempli de terre bessarabienne:- De quoi? - Comment? Tu ne m'en as pas rapporté cette fois non plus? - Anton se souvint qu'à un anniversaire, il avait promis à Matei qui descendait de réfugiés bessarabiens de lui rapporter un sachet de terre locale, histoire de lui montrer de quoi elle avait l'air. Anton mentit en disant avoir oublié le sachet chez lui. (Crudu, 2013: 267).

Anton journaliste, "jeune poète bessarabien inconnu» cherche au début du roman à placer un manuscrit auprès de Călin Vlasie, le «prospère éditeur roumain » proche de Gheorghe Crăciun qui a fondé une prestigieuse institution de l'après 1989: Editura Paralela '45. (Crudu, 2013:55). Ce romancier, éditeur, professeur d'université réapparaît dans les conversations des étudiants en lettres de Brașov, tous en proie au snobisme intellectuel du post-modernisme dont Crăciun fut un pilier dans les années $1980 \mathrm{du}$ $\mathrm{xx}^{\mathrm{e}}$ siècle. Sous l'emprise de ce modèle fréquenté en personne sur les bancs 
de la Faculté de Philologie roumaine, inquiet de sa propre valeur, Anton se compare aux autres apprentis écrivains de même extraction que lui. La nullité des post-modernes moldaves, imitateurs tardifs du courant roumain lui-même importé d'Amérique le réjouit. Forcer l'originalité en pimentant ses plagiats d'une grossière agressivité anti-roumaine? Tel n'est pas son choix au moins en début de son aventure. La première partie du roman tout à l'ébauche d'une personnalité mélancolique, sensible, réservée, coutumière d'émotions en demi-teinte montre Anton incapable de la violence verbale ordurière de son compatriote.

Il sortit le volume de Plesea de sa serviette et entreprit de le lire. Il se rendit compte en un éclair que le livre était faible et un mauvais sourire triomphant s'installa sur ses lèvres. Les quelque soixante-dix pages qui lui restaient à lire étaient remplies de clichés de poésie textualiste misérabiliste dans le genre: 'moi j'écris, moi je lis, je vous ch... sur la tête, la Roumanie est un pays d'oligophrènes qui m'inspire du dégoût et la honte d'y vivre, depuis mon neuvième étage, je pisse sur vos idéaux de ratés'. Il revint à la rédaction. Revenu d'on ne sait quelle réunion financière, Alghi feuilleta à son tour le volume de Plesea et en tira une conclusion semblable. (Crudu, 2013:88-89).

Mais après des épreuves sentimentales le rapprochant du radicalisme de ce livre agressif, menacé de rester cloué à Ungheni en Bessarabie, jeté sur le pavé littéraire tant roumain que moldave, Anton rédigera finalement en faveur de Pleșea la "pluie d'éloges» dont il transmet en pleine nuit copie à l'auteur par e-mail (Crudu, 2013: 268). La complaisance coïncide avec une étape de la prise de conscience artistique du héros / narrateur. Car le roman retrace aussi une «initiation" littéraire, l'évolution vers l'acceptation d'une identité ni bessarabienne ni roumaine mais bien «moldave» dont l'actualité politique fournit jour après jour à Anton les ingrédients nouveaux.

La fin du roman à Chișinău évoque une atmosphère intellectuelle sans pareille dans la Roumanie d'après 1989: la solidarité entre écrivains roumanophones y est peut-être ressentie comme une priorité. Dumitru Crudu témoigne que son roman a d'abord été rédigé en 1995. Subtilisé par le logeur (bessarabien) qui lui reprochait de ne pas lui avoir réglé la souslocation de sa chambre en Roumanie, il a été entièrement réécrit de mémoire, explique l'écrivain en avant-propos (Crudu, 2013: 11-13). La double datation est donc donnée comme première responsable de plusieurs versions du texte générant des anecdotes déployées sur une période de crise assez ample. Ce climat de transition engendre un cadre temporel précis et flou à la fois, s'il ne motive pas seul la psychologie des personnages. Comme dans Măcel în Georgia/ Massacre en Géorgie (2008), Oamenii din Chișinău/ Les hommes 
de Chişinău (2011), Dumitru Crudu se montre inspiré par l'actualité de sa région, ses causes, ses conséquences. Il n'en élude pas l'historique. Des détails ponctuels éclairent le flux et reflux communistes sur arrière-fond de pesanteurs tsaristes, ottomanes, provinciales roumaines successives du passé lointain. L'action est surtout centrée sur le milieu des années 1990 du $\mathrm{XX}^{\mathrm{e}}$ siècle. Au cours de cette période, l'effondrement de l'URSS apparaît comme l'événement politique majeur en Moldavie de ce fait indépendante (1991) comme en Roumanie voisine, soudain « ouverte» à l'infiltration de réfugiés. Dans les conversations à Chișinău, la candidature politique de Iourie Roșca est débattue par éclairs. Les flottements identitaires des Moldaves face aux Roumains et le positionnement des Roumains face au communisme du passé sont attribuables à une transition post-communiste ressentie en Roumanie aussi comme décevante. C'est la médiocrité dirigeante qui a rendu inévitable le retour au pouvoir de l'apparatchik Iliescu successeur de Ceausescu, comme l'explique Dumitru Crudu dans une interview explicitant ses intentions de description

d'une Roumanie historiquement datée: de la fin du mandat d'Emil Constantinescu. Les gens qui avaient investi des espoirs dans la Convention Démocrate se sont sentis trahis, ce qui a rendu possible le retour d'Iliescu. Voilà la réalité. Nous aurions tous voulu que ce soit différent mais la réalité nous a durement contredit. (Dumitrache, 2013).

Ce climat de trouble précisément, de débâcle, sinon de suites prolongées d'une ou plusieurs révolutions a attiré dans la région des deux pays roumanophones: l'Américain avide de découvrir ici la "vraie vie» dont il a eu l'intuition par contraste dans le «luxueux restaurant de son père au centre de Chicago où Saül Bellow en personne venait prendre son thé du matin» (Crudu, 2013: 226, 227). Anton n'a pas revu sa mère depuis cinq ans quand il retourne en Moldavie après avoir publié des livres de l'autre côté de la frontière. On va admirer en lui l'écrivain qui a réussi dans une langue brimée par l'URSS: seule la Roumanie peut accorder une telle reconnaissance. Une autre interview de Dumitru Crudu complète sa présentation par le roman de l'atmosphère intellectuelle bessarabienne des années 1990. Le café d'artistes et écrivains où se déroulent des scènes d'Un Américain à Chișinău se voulait un haut lieu politique:

$\mathrm{Du}$ point de vue temporel, le roman se déroule à l'époque où Iourie Roșca était 'le meilleur Roumain de Bessarabie'. La politique était alors faite aussi 'par les fêtards de Fulgușor', ce café où se réunirent pendant dix ans écrivains, journalistes, artistes de la capitale interrives. Ce café est un forum 
de l'apparence et pour certains: de l'inefficience. Mais pour d'autres, c'a été un lieu de lutte pour la libération nationale. (Pilchin, 2013).

Dans le bar pour écrivains roumains de Chișinău, Martin commandera des bières moldaves. Anton et lui considéreront ensemble le poète Eugen Cioclea, l'acteur Gheorghe Grâu attendant à une «table vide jouxtant les toilettes qu'une connaissance leur paie un café et une tartine», Nelu Apostolachioaie "seul à griffonner du papier», Ion Vădana croquant "des graines de tournesol devant des étudiants en peinture l'appelant par son prénom: Radu». (Crudu, 2013: 222,223). Un journaliste de Moldova Suverană / La Moldavie souveraine vient s'asseoir face à eux. Un scénariste du studio Moldova-Film, un rédacteur de Tineretul Moldovei / La jeunesse de Moldavie leur succèdent. Tous questionnent Martin avec une naïveté que la Roumanie moins fermée ne connaît plus: «D’où es-tu? Pourquoi es-tu venu en Moldavie? Quel âge as-tu? Comment trouves-tu les filles moldaves? Et Chișinău? Sais-tu que les Moldaves sont roumains?» (Crudu, 2013 : 226). Le journaliste Andrei Cana de Radio Europe Libre les invitera à une interview en studio. Les questions politiques censurées dont l'existence sous-tend l'atmosphère politique de la période, motive la défiance des deux groupes roumanophones dans les deux pays, sont abordées. "Chemin faisant, Andrei les pria d'éviter d'évoquer le dossier de l'Union de la Moldavie avec la Roumanie, de mentionner les glottonymes 'bessarabien' et 'roumain' s'ils ne voulaient pas lui faire perdre son travail». Le studio où travaille Andrei est la place forte d'émissions de propagande ou contre-propagande américaines (Radio Free Europe a été financée par les USA), comme le montre Andrei à Martin et Anton sans daigner expliciter les sous-entendus politiques d'une situation connue. Dans cette zone sensible, la terminologie d'obédience nationale roumaine n'est pas admise. Commenter l'histoire récente même est risqué et exige en le recours à une pesanteur langagière de l'ordre de la langue de bois.

Encore une chose, les prévint le journaliste, sachez qu'en République de Moldavie en 1992, n'a pas eu lieu une guerre russo-moldave mais un conflit armé, le conflit armé du Dniestr. C'est la terminologie politiquement correcte. Or la politique de notre poste est l'impartialité, l'équidistance (...), les instruisit Andrei face à la porte métallique d'Europe Libre où nul ne pénètre si on ne lui ouvre. 'C'est pourquoi nous qui travaillons à Europe Libre, ne vivons pas en Bessarabie mais en République de Moldavie, en République de Moldavie où il n'y a pas de Roumains mais des Moldaves. C'est compris, frères?' les instruisit encore le journaliste avant de leur ouvrir grand la porte et de les faire entrer par ordre d'importance, l'Américain d'abord, Anton à sa suite. (Crudu, $2013: 228$ ) 
La nationalité de Martin lui ouvre toutes les portes. Elle suffit à lui assurer l'avantage amoureux sur un Anton pourtant montré comme la proie consentante des plus belles filles de la Faculté de Philologie. Dès qu'il a vu l'Américain, celui-ci a d'ailleurs compris que ce «type (était) venu chercher en Roumanie et Moldavie des aventures sexuelles». Son argent, son cynisme lui permettent de flatter le vice local principal: l'alcoolisme. À peine entré dans un bar, il s'installe à une table où "pleuvent les bouteilles.» (Crudu, 2013: 227). Avant qu'on ne lui serve une bière moldave, « une belle réceptionniste l'a dévoré des yeux» (Crudu, 2013 :220). L'appât du gain n'est pas seul à motiver l'attention des Moldaves pour la sécurité d'un Martin. Peut-être attend-on de lui qu'il ait le courage de rendre public dans son livre sur Chișinău le «verrouillage» de zones du pays : de la Transnistrie aux poches impénétrables ou dangereuses des villes et villages qu'il visite aux côtés de son "protecteur».

Sans avoir encore vérifié dans les bureaux de Radio Europe Libre le prestige d'une américanité laissé intact par la propagande soviétique, Anton est exaspéré par la russité agressive du quotidien à Chișinău. Le taxi où il a fait monter Martin laisse tonitruer une radio russe et il en a honte. On le voit délibérer sur la nécessité d'élire un dirigeant évitant aux roumanophones semblable affront sonore face à un étranger.

Le chauffeur écoutait de la musique russe, commentée en russe, puissance sonore maximum et Anton rougit de ce taximétriste écoutant Ruskaïa Radio. La ville entière ne comptait pas un seul taxi où n'aurait résonné de la musique russe. Il se rappela Iourie Roșca. «Seul Iourie Roșca peut nous sauver des Russes. Il peut seul obliger ces gens à changer leur mentalité» se dit Anton dans sa tête. Je vais voter Iourie Roșca aux élections d'automne, convaincre mes parents de voter pour lui: lui seul peut nous sauver des Russes. S'il arrive au pouvoir, les gens écouteront enfin la radio roumaine en taxi, conclut Anton. (Crudu, 2013: 231, 232).

Longeant l'Académie des Sciences, Anton trouve Chișinău inchangé depuis 1992 «sinon au niveau de l'emballage». Les monuments, les édifices sont semblables, on les a tout juste débaptisés. Une place ne se nomme plus Serghei Lazo mais Décébal: du nom d'un souverain dace. Celle des Soldats Soviétiques Libérateurs s'appelle à présent «des Nations Unies». L'ancienne place Lénine est vide de sa statue et quand l'Américain aura mis fin à un besoin pressant face à l'ex- esplanade de la Jeunesse, du Monument des Komsomols, tous deux devront héler un taxi pour espérer atteindre le lycée Mircea Eliade (Crudu, 2013 : 232-235) sans doute rêvé depuis Chicago et la rencontre de Saül Bellow. Ces constatations conduisent Anton à s'enivrer, à 
se jeter sans papiers dans le train où un policier l'interpelle brutalement en l'accusant d'espionnage. Anton qui durant ses cinq années en Roumanie n'a pas écrit une ligne à ses parents, ne les a pas appelés une fois au téléphone dans son "désir de devenir roumain à tout prix, de cesser d'être moldave» est pris pour un Roumain sans pouvoir prouver son identité (Crudu, 2013:143).

- «Tu ne serais pas roumain?» demanda le flic d'un ton accusateur.

- Ton accent est roumain! Tu viens d'où en Roumanie? Qu'est-ce que tu viens chercher en Moldavie? (...)

- Je ne suis pas roumain, je suis de Ungheni. (...)

Anton apprit ainsi que ce flic-là ne pouvait pas blairer les Roumains, lui compris car cette population (...) ne pense qu'à mettre les Moldaves à genoux! (...) Anton était roumain. S'il feignait d'être originaire de Ungheni, c'était à coup sûr pour sauver sa peau. Mais le policier avait pigé du premier coup, il allait lui river son clou. Le conduire au poste parce qu'il circulait en Moldavie sans passeport. Tandis que le flic râlait, Anton s'assoupit, pris d'une étrange mollesse mais le chien le réveilla en l'accusant d'avoir écrit sur les murs du wagon: "La Bessarabie est un territoire roumain». À présent, il l'accusait d'espionner. D'être en Moldavie en mission spéciale. On était proches des élections. Anton avait été parachuté pour convaincre les gens de voter: Roșca. Incapable de mettre la main sur son passeport, sans moyen de prouver au flic son erreur, Anton se taisait. En Moldavie, tous le regardaient de travers en le prenant pour un Roumain alors qu'en Roumanie on l'identifiait comme Kagébiste et homme des Russes. (Crudu, 2013 : 239-240).

L'anti-russisme d'Anton est viscéral. L'amitié qu'il porte à Martin procède aussi du désir de l'influencer sur ce chapitre, de l'informer en tout cas des effets d'un demi-siècle d'occupation sur le quotidien de Chișinău. "-Si on buvait une bière roumaine?" propose Martin. Et il déclenche chez son ami cette démonstration amère: - «Dans ce pays, tu ne trouveras pas une goutte de bière roumaine même si tu fouilles les coins de cave à la bougie. De la bière russe, on en trouve en veux-tu en voilà, mais sache que par principe, je ne bois jamais de bière russe, tout simplement parce qu'elle est russe et les Russes, tu connais l'histoire... On peut tomber sur de la bière allemande. Tiens, je boirais bien une bière allemande.» (Crudu, 2013:220)

Las de son identité roumaine, le poète Ion Ianculovschi inscrit en doctorat à Timișoara revient à son tour changer son passeport, l'ancien étant périmé. À la faveur sans doute d'une transposition administrative des caractères cyrilliques en alphabet latin, il va remplacer les deux " $c$ " de son nom par deux " $k$ ". Ion Ianculovschi sera désormais Ivan Iankulovski (Crudu, 2013: 127). A l'étranger, les Moldaves ont si honte de leur identité qu'ils mentent 
à son propos. "Anton (...) raconta qu'à Vienne, il se faisait passer pour tchèque pour éviter d'éveiller la suspicion des Autrichiens.» (Crudu, 2013: 126). Dans un bus roumain, il fabule sur son origine au mépris de toute crédibilité:

- Tu as un billet? demanda le chauffeur.

Oui, j'en ai un. Le voilà. Il le lui montra avec ennui.

Tu vas à Braşov?

Oui, je vais jusqu’à Braşov.

Tu ne viendrais pas de République de Moldavie par hasard?

Tous le fixaient, le scrutant avec la grande curiosité qu'on montre face à un extraterrestre.

Il nia. Non, je ne suis pas de République de Moldavie, je suis roumain. Il observa que tous respiraient avec soulagement.

Tu parles comme quelqu'un de Chișinău.

C'est vous qui le dites.

Possible. Tu es d'où?

De Târgu Secuiesc («Bourg sicule»), jeta-t-il. C’est ce qu'il disait toujours quand on l'interrogeait sur son lieu d'origine. Pourvu que personne de Târgu Secuiesc ne soit monté dans ce bus! Si c'est le cas, je suis brûlé, se dit Anton. Mais personne n'était de Târgu Secuiesc et son mensonge passa comme une lettre à la poste. À la différence de l'homme du train, le type ne le questionna pas sur le nom de sa rue. Il voulait seulement s'assurer de n'avoir pas laissé monter un Moldave d'au-delà du Prut.

- Les Moldaves de derrière le Prut ont envahi la Roumanie, Monsieur. On ne respire plus dans ce pays. Frère, ils sont partout. Partout. Où qu'on regarde, on tombe sur un frère d'au-delà du Prut cherchant à vendre quelque chose. Ils veulent tous vendre quelque chose, M'sieur!

- Pour être sincère, moi non plus je ne peux pas les voir, glissa un monsieur à moustache noire.

- Je suis comme vous, dit Anton à l'unisson. Il se réjouissait que nul dans ce bus n'ait détecté son mensonge. Son identité moldave inspirait à Anton la même honte qu'un vêtement usagé. Des racines moldaves si incommodantes, si dérangeantes (...) Les Sicules parlent avec un accent et les Roumains ne les fréquentent guère. Aussi Anton préférait-il se faire passer pour Sicule que dire qu'il venait d'au-delà du Prut, ce qui aurait autorisé les gens à projeter sur lui leur répulsion anti-Moldave, à le traiter en bouc émissaire de tous les Moldaves d'au-delà du Prut (...) (Crudu, 2013: 76-77).

Délivrée de Ceaușescu, du communisme, la Roumanie connait-elle une liberté de mœurs, une prospérité qu'un citoyen de l'ex-Union Soviétique peut prendre pour le luxe, l'abondance de l'Occident? Par contraste, la Moldavie 
de l'après 1992, n'est pas seulement violente, soupçonneuse, misérable, arriérée: le racket y est pratiqué par les représentants de la loi. Le policier qui croit Anton roumain va lui voler ses chaussures. Il est vrai que le protagoniste a de lui-même proposé cette pièce de son habillement à l'investigation ou au pourboire en les prétendant venues d'outre Atlantique:

Prenez-les si elles vous plaisent! Le flic s'en saisit, les scrutant de toutes parts avec intérêt. Il tira aussi sur le talon pour vérifier s'il se décollait. - Elles sont américaines, mentit Anton, car les chaussures étaient roumaines. Elles sont originales et surtout, elles sont neuves. Un ami américain m'en a fait cadeau après avoir baisé ma copine. Un pied en l'air, le flic se déchaussa pour les mesurer. Elles lui allaient à merveille. Sans les retirer, il sortit du wagon d'un pas alerte ainsi chaussé. (Crudu, 2013: 241).

À la poste non loin du village, des vieillards piétinent pour accéder à l'arrivage épisodique de colis. Chacun rentrera chez soi muni d'un paquet «de riz, de macarons, d'huile, de sucre» expédié de l'étranger par un proche. "Cinq ans plus tôt, Anton avait assisté ici à une scène similaire: sa mère était revenue avec cinquante kilos de sarrasin envoyés par sa sœur vendeuse à Moscou. Aujourd'hui, cette sœur envoyait un sac de pommes de terre et sa mère en était enchantée.» (Crudu, 2013:244). Le nombre de Moldaves travaillant au noir à l'étranger atteint à présent le demi-million. «Bientôt toute notre région sera changée en immense désert» affirme la mère d'Anton. Nulle pension n'a été perçue par un retraité depuis plus de six mois et il en va sans doute de même pour les salaires (Crudu, 2013:250).

\section{Linguistique: bilinguisme, diglossies, moldovénismes, parades face aux «linguicides»}

La zone n'est pas si vide que des élèves du groupe scolaire voisin - ne viennent réclamer à l'écrivain de réciter ses poésies: il les interprétera dans le roumain sans accent acquis à Brașov. Dans le public, se trouve Monsieur Lefter, le «meilleur locuteur roumain de Flutura, un homme cultivé lisant beaucoup». Ce directeur d'école prononce les « $g$ » comme des « $j$ » sans que le héros comprenne pourquoi. Mais

Anton fut moins déboussolé quand il eut accédé au livre de Gheorghe Negru intitulé La politique linguistique de la R.S.S de Moldavie que lui offrit son auteur à Fulgușor (...). Negru y expliquait que «la décision d'introduire l'affriquée " $g$ » avait été adoptée en 1967 ». Avant cette date par conséquent, la lettre " $g$ » n'existant pas dans l'alphabet cyrillique du moldave, le son " $g$ » en avait été éliminé aussi. Tous étaient obligés de le prononcer « $j »$. Monsieur Lefter avait reçu son diplôme universitaire en 1965, à l'époque où toute 
personne décidée à s'élever socialement se devait de remplacer « $g$ » par « $j$ ». La mère d'Anton manquait d'ambition et c'est pourquoi elle avait toute sa vie prononcé " $g$ " là où le roumain requiert de prononcer " $g$ ". D'ailleurs, à la différence de Monsieur Lefter, elle avait abandonné l'école en sixième classe. Si elle avait achevé son cycle scolaire, elle serait sans doute venue à s'exprimer comme lui. (Crudu, 2013: 250).

Des considérations sur des hybridations du roumain et du russe, sur les formes flottantes du dialecte moldave, leurs emplois en fonction des fluctuations psychologiques des protagonistes, eux-mêmes en butte aux pressions linguistico-politiques du passéet du présent, émaillent les péripéties. C'est aussi sur cette forme d'exotisme que l'Américain est venu enquêter.

Comment trouvez-vous Chișinău? Lui demanda Angela Gonța, quand ils se promenèrent sur l'allée des Classiques du Parc Stefan cel Mare. Martin répondit qu'il aimait Chișinău comme une poupée russe en qui coexistent le nouveau et l'ancien, l'Asie et l'Europe, la civilisation et la barbarie. (Crudu, 2013: 255).

Comme Nicoleta Esinencu, Dumitru Crudu use de la juxtaposition des deux langues: le russe et le roumain transcrits en caractères latins, pour démontrer le bilinguisme de ses personnages. Il inverse donc la situation linguistique de l'époque soviétique obligeant les roumanophones à transcrire leur langue latine en cyrilliques. Comme chez la dramaturge, ces transcriptions ne sont pas traduites, elles ont donc pour fonction de représenter aux yeux du lecteur romanesque de simples enchaînements de sons. À Brașov, où les Bessarabiens apparaissent comme des exotes, un dialogue mi-roumain mi-russe de plusieurs pages s'engage entre le barman Marian et le héros:

Chaque fois qu'il tombait sur un Bessarabien, Marian lui faisait écouter de la musique russe, engageait la conversation en russe. Avec Anton, il avait fait de même. Face aux Roumains, il s'exprimait dans un roumain sans accent, aussi nul ne l'aurait cru originaire de Bessarabie. Avec les Bessarabiens, il parlait russe par nostalgie de l'Union Soviétique. Mais il ne revenait plus jamais là-bas, par crainte des mafieux. (Crudu, 2013: 43-45).

Aux yeux d'Anton dont le roman montre pourtant la rancœur anti-russe sans fléchissement, ce regret de l'Union Soviétique n'a rien d'absurde. Tel un personnage de l'essai «Născut în RSS / Né en URSS» de Vasile Ernu publié en 2006, il écoute Marian par simple politesse ou mélancolie nostalgique à son tour ("Anton se mit à manger dans le seul but de l'entendre parler». - Crudu, 2013 : 45) alors qu'il supportera fort mal en Moldavie toute expression dans l'ancienne langue dominante. 
Plusieurs formes de duplicité se lient aux utilisations du russe, du dialecte moldave, du roumain parlé avec ou sans accent par des Moldaves cachant leur identité, glissant d'une appartenance à l'autre face à des compatriotes sans que leurs interlocuteurs roumanophones saisis d'angoisse sachent à quoi s'en tenir. À la fin du roman, la transcription des propos de Vlad met en évidence un accent dialectal changeant les « $e$ » en " $i$ », les " $a$ » en « $\hat{\imath}$ », écrasant les consonnes avant que ce personnage n'enchaîne en russe avec une agressivité brutale:

- Je te le dis sincèrement, Vlad! - Je ne m'appelle pas Vlad mais Vovcic. Menea Vovcic zavut moi drug et non Vlad! Tu as compris? - Mais à Brașov, tu me disais t'appeler Vlad! - À Braşov, j'étais peut-être Vlad mais pas ici! (...) - Je t'ai vu, frère! Lui dit Vlad dans un roumain parfait mais dès que le garçon eût débarrassé les bouteilles vides, il revint à son mélange moldaveroumain. (Crudu, 2013: 195 et 197).

Deux pages après ce revirement, Anton recompose comme dans un puzzle le tableau de la fausseté de Vlad, dénoncé par son aptitude au maquillage linguistique.

L'écoutant, Anton réalisa que Vlad était comme un voleur aux papiers en règle. Sans doute, la police était-elle déjà sur ses traces. Voilà pourquoi il fuyait vers Chișinău. Non parce qu'il avait vendu sa voiture quoiqu'il ait sans doute réellement vendu cette dernière. Alors même que tous les après-midi, il piétinait sur le seuil des organisations patriotiques pour s'y plaindre de l'oppression des Russes sur les Bessarabiens. (Crudu, 2013:201).

Le chauffeur de la Volga brillante où montent Anton et l'Américain Martin pour traverser Chișinău, leur confie avec le même accent moldave émaillé d'interjections dialectales ses impressions politiques sur des patriotes roumains patentés à l'aura de martyrs - dont les écrivains Grigore Vieru, Leonida Lari - en leur recommandant le candidat déjà préféré par Anton.

Dans l'habitacle résonnait Radio Semi. Le chauffeur leur conseilla de voter Iourie Roșca. Tous les autres démocrates sont (...) de misérables Kagébistes. La femme de Valeriu Matei n'a-t-elle pas été prise main dans le sac à la douane? Dabija, Vieru ou Lari, qu'en dire? Des profiteurs ordinaires. Moi, j'ai confiance en Iourie Roșca et à part lui en personne. Lui seul peut réaliser l'Union (...) Qu'est-ce que tu en penses? - I don't understand romanian - Traduis donc! Iourie Roșca est le meilleur roumain de Bessarabie. C'est un grand nationaliste (...) Qu'ajouter? Iourie Roșca plaisait terriblement à Anton aussi mais il se méfiait de Radio Semi. (Crudu, 2013: 216).

L'expression nationale "grai moldovenesc" joue son rôle dans les passions amoureuses du roman: une sorte de chaîne racinienne. Anton, fou 
d'Olga est aimé de Lora avant de se résigner à s'intéresser à Irina plus terne que les deux premières mais plus fiable. Toutes sont moldaves cependant, comme si la langue était le nœud de la seule relation amoureuse possible: en endogamie linguistique.

Anton, je suis folle de toi depuis que je t'ai vu. Oublie cette putain et soyons ensemble. Tu veux? Tu veux être avec moi? (...) L'entendre parler moldave lui coupa le sifflet. - Oui, je suis bessarabienne. Tu ne savais pas? - Comment l'aurais-je su? Avec ton parfait accent de la Dâmbovitsa, tous te croient bucarestoise. - Il y a deux ans, j'ai terminé l'Académie Militaire à Bucarest et je suis restée en Roumanie. Mais mon lieu d'origine, c'est Ungheni. Personne ne le sait. Tu es le premier. (Crudu, 2013:159).

\section{Dans la ligne du fracturisme: les vraies ambitions du roman}

Interrogé sur sa conception du succès littéraire, Dumitru Crudu témoigne qu'il «consiste à vendre des livres, d'autant que les auteurs moldaves dans ce cas se comptent sur les doigts de la main»(Crudu/ Borzin, 2013). La littérature bessarabienne serait caractérisée par «une absence de traditions littéraires propres» pour des raisons géopolitiques plus qu'historiques. Elle est marquée aussi par «le mélange culturel» qui est aussi son « unique tradition viable» (Crudu/ Pilchin, 2013). Il n'existe pas aujourd'hui de courant littéraire bessarabien assez fort pour qu'Un Américain à Chișinău s'y encadre (Crudu / Dumitrache: 2013). Le roman se situe dans un parcours théorique et stylistique privé cependant manifesté sur le sol roumain ("c'est un roman post-fracturiste»-Crudu/Dumitrache, 2013). Quant aux raisons d'être du fracturisme lancé en 1999 à Brașov par deux auteurs moldaves dont Crudu lui-même, elles sont récapitulées comme une volonté d'affirmation contre les post-modernes de Roumanie mais aussi comme un mode d'évolution créative jouant de l'acceptation du traumatisme, de la rupture. À ce titre, le fracturisme et ses suites devrait ou aurait dû concerner des artistes autres que moldaves.

Quand Marius Ianuș et moi avons signé le manifeste du fracturisme, nous étions en pleine guerre littéraire contre les auteurs des années 1980. Nous voulions nous séparer d'eux pour affirmer notre propre autonomie esthétique. Peut-être l'a-t-on oublié aujourd'hui mais à l'époque, tout jeune poète pointant à l'horizon était affilié au courant des années 1980 s'il n'était pas déclaré épigone des 80 ards. Ce n'est pas uniquement notre mérite, c'est sûr, mais aujourd'hui il est possible de parler du groupe fracturiste, des «misérabilistes», d'une génération des années 2000 distincte de celle des années 1980 ou 1990. Nous avons eu aussi le mérite de tirer le rideau sur les 
thèmes tabous, de radicaliser, décomplexer le langage poétique, nous avons déplacé l'accent posé jusque-là sur les réalités décrites en le faisant porter sur celui qui les décrit et sa marginalité assumée. Quand nous sommes partis en guerre contre les 80ards (cela ne signifie pas que nous ne voyons pas Mușina, Mureșan, Danilov, Cărtărescu, Bucur, Crăciun, Vlad comme de grands écrivains mais nous avons lutté pour être perçus comme différents), je plaisantais en disant à Marius Ianuș que le fracturisme justifierait son existence le jour où nous nous frapperions l'un l'autre. C'est arrivé plus tard. Aujourd'hui, le courant des années 2000 (douămiismul) a déjà donné quelques grands romans, quelques livres de poésie exceptionnels, des essais fondamentaux et il commence à faire partie du canon. (Crudu / Dumitrache : 2013)

La volonté de pénétration (ou de fracassement) de la littérature roumaine contemporaine de Roumanie par le fracturisme moldave a donc été manifeste dès le début de ce courant. On note dans l'explication de Dumitru Crudu la division en décennies littéraires confortant le propos de l'historien littéraire Petru Negură quand il insiste sur le comportement générationnel marqué des écrivains d'au-delà du Prut. Ce trait caractérise-t-il la vie littéraire en Moldavie après la chute de l'Union Soviétique mais non en Roumanie? L'histoire littéraire roumaine rédigée en Roumanie d'après 1945 a nettement découpé aussi les principales générations littéraires du communisme (années 1960, 1970, 1980) dans une reprise du descriptif caractérisant déjà la vie culturelle roumaine d'avant la deuxième guerre mondiale. La majeure part de la critique a en effet insisté sur la polarisation générationnelle des jeunes auteurs roumains des années 1930, presque tous axés sur le goût de l'expérience vécue en dépit des violents clivages idéologiques. Cependant nulle génération roumaine de Roumanie revendiquant l'appartenance aux années 1990 ou 2000 n'a prétendu se faire connaître à l'étranger, à notre connaissance. Les auteurs moldaves se comporteraient donc à cet égard en francs-tireurs, en cavaliers seuls par crainte ou dépit d'avoir été minorés d'avance (serait-ce par l'affiliation abusive à un courant roumain) en tant que groupe distinct des Roumains de Roumanie pour des raisons d'identification nationale ou idéologique plus que poétique proprement dite. On rappellera ici que Savatie Bastovoi par exemple, si différent de Dumitru Crudu a bénéficié de l'attention favorable de Mircea Cărtărescu, dit postmoderne, lors de ses débuts poétiques.

Interrogé sur la question de l'engagement qui a départagé en deux camps les artistes politisés ou non du $\mathrm{xx}^{\mathrm{e}}$ siècle sans tenir compte à temps $\mathrm{du}$ caractère coercitif du réalisme socialiste, Dumitru Crudu affirme sa 
prédilection pour les problématiques de l'humain et du nouveau. L'humain qu'il privilégie n'apparaît pas comme séparé du social. De même, il peut opter pour un nouveau incluant la modernité victorieusement affrontée par le communisme, selon Vasile Ernu - "L'Union Soviétique n'a pas été seulement un pays mais bien davantage: elle a été le plus grand projet politique utopique de la modernité» (Ernu, 2013: 8) - jusque dans les formes d'art conventionnelles mais de grande audience que cet empire a développées.

(J'aime) les romans dans lesquels on entend le mugissement, le tumulte de la société. Ce mugissement s'entend même dans des romans très expérimentaux comme «Ulysse » de Joyce. Je les préfère. Je les préfère aux romans intelligents et sophistiqués où l'aveuglant spectacle stylistique rejette la vie dans l'ombre et la vampirise. Je ne suis pas fasciné par la nouveauté littéraire en soi mais par la nouveauté de l'existence, la nouveauté humaine, la nouveauté de la respiration, au bout du compte. Rien n'a autant de prix que les lumières et les ombres des relations entre les hommes. Rien n'a autant de prix que les battements d'un cœur humain. C'est pourquoi j'aime à la folie les romans où je peux entendre ces battements-là. (Crudu / Dumitrache: 2013).

On observe le goût de l'écrivain pour le lexique et les métaphores de la corporalité. Le terme fracturisme renvoie à la fois à un phénomène géologique et à un accident du corps. Les battements d'un cour humain ont de puissantes connotations poétiques d'ordre lyrique mais le syntagme renvoie aussi - dans le contexte du paradis maffieux moldave du racket d'organes - à la nécessité d'une expression artistique propre à une société où la survie corporelle par transfert de parties jusque-là vues comme incessibles doit être envisagée au niveau collectif. De même, le terme respiration renvoie à la sacralisation du corps humain par le mysticisme chrétien orthodoxe pour lequel le souffle est lié à Dieu, à la vie. On songe pour finir à l'utilisation du terme organique dans l'historiographie diplomatique, politique, culturelle des relations roumaines avec le pouvoir tsariste (Règlement organique par exemple). Ce terme assume l'évidence d'un rapport démontré entre microcosme et macrocosme outre la nécessité d'application au champ politique de réalités biologiques. Au-delà de ces illustrations de l'appartenance à un univers mental roumain désigné par le langage usuel, trivial de tout roumanophone, Dumitru Crudu tente d'évidence dans sa littérature la transposition d'une idée "présente de fait dans tous ses livres: chaque espace culturel a ses circonstances littéraires». L'une des "circonstances littéraires» moldaves serait l'implication réciproque de la culture roumaine et de la culture russe, réalisée par le passé en religion sans doute mais aussi aujourd'hui 
sous une forme sociale inédite en République de Moldavie. La particularité bessarabienne tient

au fait que certains nient les contributions apportées par les Russes à la culture bessarabienne tandis que d'autres limitent la culture bessarabienne aux influences russes. Or les personnages de Dumitru Crudu sont des mélanges réussis de ces deux espaces culturels. En ce sens, les livres de l'auteur bessarabien sont actuels comme jamais. En Bessarabie, coexistent aujourd'hui des Roumains locuteurs de russe et des Russes locuteurs de roumain: c'est une situation ethnolinguistique pratiquement inconnue jusqu'à ce jour. (Pilchin, 2013).

Les romans de Dumitru Crudu comme les livres de Savatie Bastovoi, Nicoleta Esinencu, Vasile Ernu peuvent relever de la description d'un univers de la décolonisation ou post-colonisation. Il est sans doute possible de raccorder leur contenu à une expérimentation des hybridations culturelles présentes dans toute interpénétration de cultures dominées et cultures dominantes. Toutefois dans une époque où abondent les informations artistiques composant avec les modes de transmission visuels, le trait le plus original de l'œuvre de Dumitru Crudu nous paraît être son insistance à privilégier un aspect de la réalité définitoire de la littérature, art usant de la langue pour seul outil. Les personnages d'Un Américain à Chisinău sont largement décrits dans le rapport qu'ils entretiennent avec le langage, lui-même étroitement déterminant du niveau de culture dont ils ont pu bénéficier, des chances qui leur sont offertes un moment mais se révèlent des leurres.

C'est l'expérience langagière du roumain interdit de transcription en caractères latins, interdit aussi de contact avec la langue de l'État roumain qui motive la quête linguistique et culturelle d'Anton en Roumanie. Là, il va s'instruire, comparer son expérience à celle des natifs autorisés à penser et écrire dans une langue qui est aussi la sienne - quoique sous une forme ne l'autorisant ni à créer, ni à légiférer linguistiquement parlant -. C'est sa révolte, son humiliation renforcées par l'impression d'avoir traversé un linguicide (pour user du terme forgé par Claude Hagège) impossible à définir ou nommer qui expliquent ses pérégrinations, ses partis pris amoureux et pour finir sa chute au fond d'une Moldavie bilingue, dialectophone, au moins triglossique donc mais sienne. Jusqu'à la fin du roman, l'auteur continuera de noter les comportements langagiers de l'entourage d'Anton, les sortes d'hallucinations que ces derniers provoquent en lui, insistant sur ce qui apparaît comme l'idiosyncrasie moldave: une expérience langagière non partagée mais engageant jusqu'à l'âme des Roumains et des Moldaves. 
Historicisme politique linguistique, incommunicabilité, modelage mental de la réalité par la dénomination, démonstration des dimensions charnelle ou à l'inverse spirituelle de l'acte langagier: toutes ces abstractions sont intégrées par le thriller de Dumitru Crudu dans sa figuration de l'univers des personnages comme dans les portraits. Sans omettre la conclusion en somme humaniste - seul happy end de cette sombre aventure justicière - proposée au lecteur par l'art de Dumitru Crudu une fois son livre refermé... Sans les Bessarabiens rendus psychologiquement infirmes par la mutilation linguistique, la haine justifiée des Russes, l'imitation des pires mœurs de ces derniers et tant d'autres faiblesses, l'univers linguistique, culturel, spirituel, moral russe dans ce qu'il a d'exemplaire pourrait-il continuer d'être transmis ou sauvé?

\section{Bibliographie}

Baștovoi, Savatie, (Ieromonah), 2010, Diavolul este politic corect, roman, Editura Cathisma, București.

Baștovoi, Savatie, 2012, Les lapins ne meurent pas, roman traduit du roumain par Laure Hinckel, Éditions Jacqueline Chambon.

Baștovoi, Savatie et Colosimo, Jean-François, 2013, România ïngerilor, O discutie la Saint-Serge, Institutul Ortodox din Paris, Editura Cathisma, București.

Boia, Lucian, 1999, History between truth and Fiction- Playing with the past In "Explorations into the Imaginary", Plural, The Romanian Cultural Foundation, Culture and Civilization, Editor in Chief Aurora Fabritius, Bucarest.

Boia, Lucian, 2000, La mythologie scientifique du communisme, Essai, Les Belles Lettres, Paris.

Boia, Lucian, 2012, De ce este România altfel?, Editura Humanitas, București.

Boia, Lucian, 2013, Sfârșitul Occidentului? Spre lumea de mâine, eseu,Editura Humanitas, București.

Crudu, Dumitru, 2013, Un American la Chişinău roman. Casa de pariuri literare, Bucarest.

Ernu, Vasile, 2013, Născut în URSS, essai, Editia a IV a, Postfaţă de Sorin Antohi Polirom, Iași.

Cazacu, Matei et Trifon, Nicolas, 2010, Un état en quête de nation: la République de Moldavie', essai. Cartes réalisées par Vincent Vacarisas. Éditions Non Lieu, Paris.

Esinencu, Nicoleta, 2011, $7 \mathrm{~km}$ dans Odessa Transfer, nouvelles, traduit du roumain par Laure Hinckel, chroniques de la mer Noire (textes de Neal Ascherson, Attila Bartis, Mircea Cartarescu etc.), Éditions Noir sur Blanc, Lausanne. 
Esinencu, Nicoleta, 2006, FUCK You Europa! Sans sucre, traduit du roumain par Mirella Patureau, Éditions l'Espace d'un instant, Paris.

Fondane, Benjamin, Les révélations de la mort dans Iudaism si Elenism (Traduit ici du roumain par Hélène Lenz).

Goma, Paul, 2001, Profil bas' roman traduit du roumain par Helene Lenz. Éditions des Syrtes, Paris.

Manea, Norman, 2007, L'heure exacte et autres nouvelles traduites du roumain par Alain Paruit, André Vornic, Marie-France Ionesco et Odile Serre, Fiction et Cie, Seuil, Paris.

Miller, Martin, 2001, Freud au pays des soviets, essai traduit de l'anglais (États-Unis) par Sylvette Gleize. Collection Les Empêcheurs de penser en rond, Seuil, Paris.

Negură, Petru, 2009, Ni héros ni traîtres: les écrivains moldaves face au pouvoir soviétique sous Staline'. L'Harmattan, Paris.

Sântimbreanu, Mircea, 2011, Mama mamutilor mahmuri, nouvelles, Editura Dacia, $3^{\mathrm{e}}$ édition, Cluj-Napoca.

Tănase, Virgil, 2012, Dostoievski. Folio biographies n²92, Éditions Gallimard.

Thorez, Paul, 1982, Les enfants modèles, Éditions Lieu Commun, Folio nº 1538.

Vosganian, Varujan, Le livre des chuchotements (Cartea șoaptelor, Éditions Polirom, Iași, 2009) Roman traduit du roumain par Laure Hinckel et Marily le Nir, Éditions des Syrtes, 2013 pour la traduction française.

\section{Sitographie}

Baștovoi, Savatie, Biografie Savatie Bastovoï Page web personnelle de l'auteur. (C) 1999-2003, http://agonia.ro/index.php/author/006836 consulté le 01/01/2013.

Baștovoi, Savatie, Savatie Bastovoi: nebunu http://savatie.wordpress.com/ consulté le $02 / 10 / 2012$.

Gombos, Stelian, Interviu cu Parintele Savatie Bastovoi (Dialog de suflet realizat la Chisinau de Stelian Gombos) - après juillet 2009-) 26 pages consultées le 10/09/2013 http://www.crestinortodox.ro/interviuri/interviu-parintele-savatie-bastovoi.

Ianus Marius, Dumitru Crudu, Ionut Chiva, Manifestul fracturist, consulté le 06/11/2013, http://www.poezie.ro/ index.php/ essay/202813/index.html.

Gorea, Ovidiu, Les années de plomb. Pionniers pour préparer l'avénement de l'homme nouveau, p. 20-23, http://www.lesnouvellesderoumanie.eu/images/2007-04-01_2pdf, consulté le 31 août 2013.

Ribardiere, Gilles, Une pièce de Nicoleta Esinencu à Paris, consultée le 05/02/2013, http://www.moldavie.fr/spip.php?article1456

Rusu, Ileana, Nicoleta Esinencu. Copilul teribil al lui Esinencu, VIP Magazin, septembrie 2005, nr.17, http://www.vipmagazin.md/profil/Nicoleta_ESINENCU/ consulté le 9 septembre 2013. 
Simon, Catherine, Les lapins ne meurent pas: une enfance moldave, consultée le 20 février 2013 http://www.lemonde.fr/livres/article/2012/01/05/les-lapins-nemeurent-pas-de-savatie-bastovoi_1625796_3620.html.

Târziu Claudiu (interview réalisée par Claudiu Târziu, pour la revue Rost - sans date)

Parintele Savatie Bastovoï - Potmodernism în rasa calugareasca, consultée le 30/09/2012, http://www.crestinortodox.ro/interviuri/parintele-savatie-bastovoi-postm

Quiriconi, Sabine, L'étoile du Nord présente du 17 au 21 novembre 2009 «All RH+» (A II Rhésus positif) texte de Nicoleta Esinencu paru en 2007 en édition bilingue, Editura Idea, Cluj, Editura Walther König, Köln. (Mirella Patureau traductrice, Résumé et Intentions de mise en scène, notes de scénographie de Michèle Harfaut, metteur en scène. Présentation de l'équipe: Nicoleta Esinencu auteur, Michèle Harfaut metteur en scène, Miglen Mirtchev comédien, Mirella Patureau traductrice, Sabine Quiriconi dramaturge, Julien Kosellek conception lumière, Loraine Djidi scénographe, David Geffard, conception sonore.)

Fol-en-Christ, Wikipedia. consultée le 8 oût 2013 http://fr.wikipedia.org/wiki/Fol-en-Christ 